\title{
Conceptual Design Parameters for HFIR LEU U-Mo Fuel Conversion Experimental Irradiations
}

\section{March 2013}

Prepared by:

David Chandler

David Cook

Germina llas

Prashant Jain

David Renfro

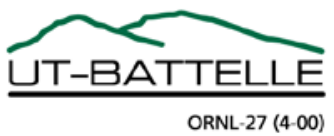





\title{
Conceptual Design Parameters for HFIR LEU U-Mo Fuel Conversion Experimental Irradiations
}

\author{
David Chandler \\ David Cook \\ Germina Ilas \\ Prashant Jain \\ David Renfro
}

Date Published: March 2013

\author{
Prepared by \\ OAK RIDGE NATIONAL LABORATORY \\ Oak Ridge, Tennessee 37831-6283 \\ managed by \\ UT-BATTELLE, LLC \\ for the \\ U.S. DEPARTMENT OF ENERGY \\ under contract DE-AC05-00OR22725
}





\section{CONTENTS}

Page

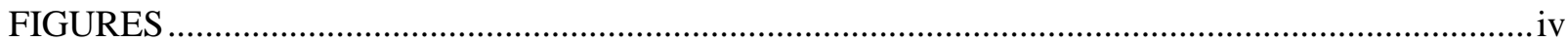

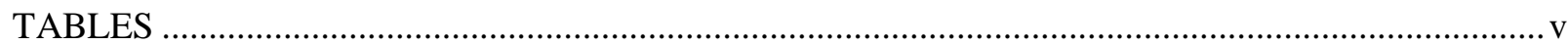

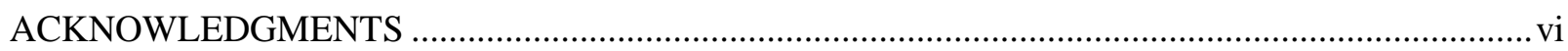

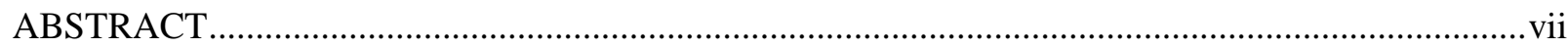

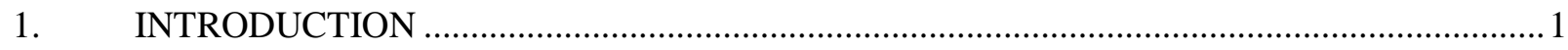

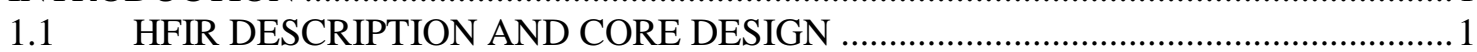

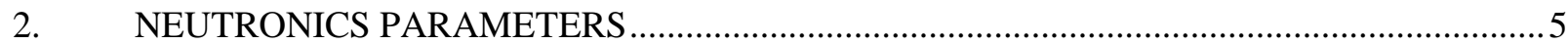

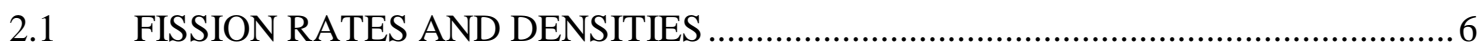

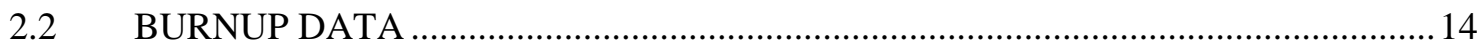

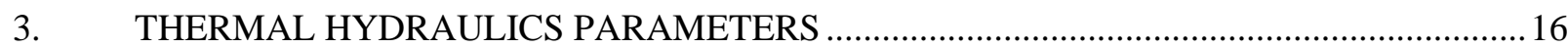

3.1 HFIR STEADY-STATE HEAT TRANSFER CODE (HSSHTC) ANAYSIS ..............16

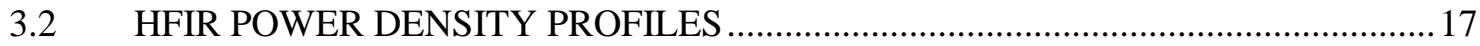

3.3 HFIR FUEL PLATE SURFACE TEMPERATURE PROFILES ...............................20

$3.4 \quad$ HFIR FUEL PLATE SURFACE HEAT FLUX PROFILES.......................................26

3.5 COMPARISON OF HSSHTC RESULTS TO HFIR COMSOL

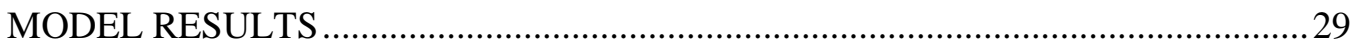

3.6 THERMAL CONDITIONS AT LOCATIONS OF PEAK FISSION RATE AND ACCUMULATED FISSION DENSITY ...............................................................

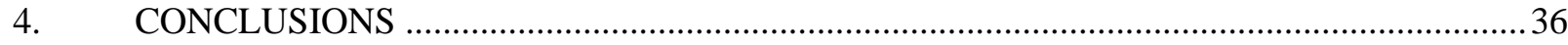

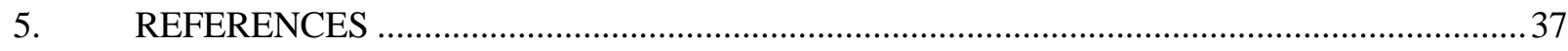




\section{FIGURES}

Figure

Page

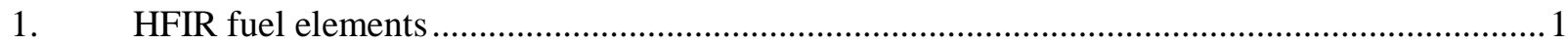

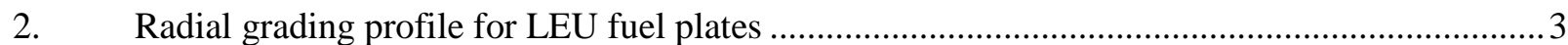

3. Axial grading profiles for LEU fuel $(0-3 \mathrm{~cm}$ from bottom of fuel element)..............................4

4. Graphical representation of LEU fission rate density (fissions $/ \mathrm{cm}^{3} \mathrm{UMo}-\mathrm{s}$ ) at

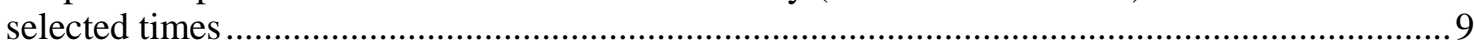

5. BOC (left) and EOC (right) fission rate density (fissions $/ \mathrm{cm}^{3}$ UMo-s) radial profiles...............10

6. BOC (top) and EOC (bottom) fission rate density (fissions $/ \mathrm{cm}^{3}$ UMo-s) axial profiles ............10

7. Graphical representation of LEU accumulated fission density (fissions $/ \mathrm{cm}^{3} \mathrm{UMo}$ ) ..................12

8. Accumulated fission density (fisions $/ \mathrm{cm}^{3} \mathrm{UMo}$ ) radial profiles ............................................13

9. Accumulated fission density (fissions $/ \mathrm{cm}^{3} \mathrm{UMo}$ ) axial profiles.............................................13

10. Graphical representation of ${ }^{235} \mathrm{U}$ atom percent burnup .........................................................14

11. Local LEU fuel power density (watts/ $\mathrm{cm}^{3} \mathrm{UMo}$ ) profiles versus time in HFIR cycle ................18

12. BOC (left) and EOC (right) power density (watts/ $\mathrm{cm}^{3} \mathrm{UMo}$ ) radial profiles...........................19

13. BOC (top) and EOC (bottom) power density (watts $/ \mathrm{cm}^{3} \mathrm{UMo}$ ) axial profiles............................19

14. Normalized local-to-average power density for BOC inner and outer elements .......................20

15. Axial profile of plate surface temperature at BOC for inner and outer elements ......................22

16. Axial profile of plate surface temperature for EOC, inner and outer elements .........................23

17. Three-D profiles of plate surface temperature for inner element at BOC and EOC ..................24

18. Three-D profiles of plate surface temperature for outer element at BOC and EOC...................25

19. Heat flux distribution for inner element at BOC, peak xenon (day 1), and EOC .....................27

20. Heat flux profiles for outer element at BOC, peak xenon (day 1), and EOC ...........................28

21. Three-D plot of outer element heat flux distribution at peak xenon (day 1)............................29

22 COMSOL profiles of plate "hot-side" surface temperature $\left({ }^{\circ} \mathrm{F}\right)$ for the inner and outer

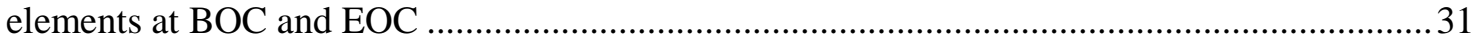

23. COMSOL profiles of fuel meat certerline (peak) temperature $\left({ }^{\circ} \mathrm{F}\right)$ for the inner and outer

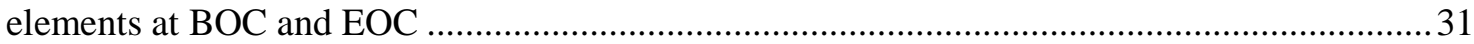

24. COMSOL profiles of plate "hot-side" surface heat flux $\left(\mathrm{W} / \mathrm{cm}^{2}\right)$ for the inner and outer elements at BOC and EOC ...... 


\section{TABLES}

Table

Page

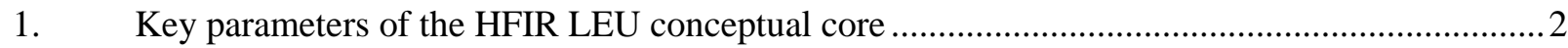

2. Radial fuel regions in the MCNP model for HFIR LEU ......................................................2

3. Radial fuel regions in the MCNP model for HFIR LEU ...............................................5

4. Axial fuel regions in the MCNP model for HFIR LEU ........................................................5

5. Maximum fisison rate density during cycle and accumulated fission density ...........................6

6. Fission rate density ( $\mathrm{x} 10^{15}$ fissions $/ \mathrm{cm}^{3} \mathrm{UMo}-\mathrm{s}$ ) for HFIR LEU at BOC ................................ 7

7. Fission rate density ( $\mathrm{x} 10^{15}$ fissions $\left./ \mathrm{cm}^{3} \mathrm{UMo}-\mathrm{s}\right)$ for HFIR LEU at EOC................................. 8

8. Accumulated fission density $\left(\mathrm{x} 10^{21}\right.$ fissions $\left./ \mathrm{cm}^{3} \mathrm{UMo}\right)$ for HFIR LEU at EOC ......................11

9. $\quad{ }^{235} \mathrm{U}$ atom percent burnup for HFIR LEU core .................................................................15

10. Peak surface temperatures, heat fluxes, and fuel meat temperatures over the fuel cycle HSSHTC and COMSOL results ...................................................................................... 32

11. Determination of peak U-Mo meat temperatures at core axial centerline using HSSHTC results.

12. Peak surfce temperatures, heat fluxes, and fuel meat temperatures for the innter element

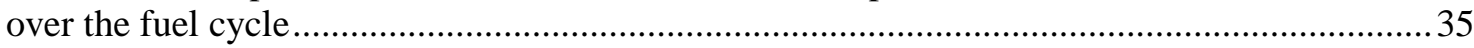

13. Peak surface temperatures, heat fluxes, and fuel meat temperatures for the outer element over the fuel cycle 


\section{ACKNOWLEDGMENTS}

The authors would like to acknowledge that the support for this project was provided by the Global Threat Reduction Initiative, Reduced Enrichment for Research and Test Reactors Program, a program of the Nuclear National Security Administration, U.S. Department of Energy. 


\begin{abstract}
The High Flux Isotope Reactor (HFIR) is a versatile research reactor that is operated at the Oak Ridge National Laboratory (ORNL). The HFIR core is loaded with high-enriched uranium (HEU) and operates at a power level of 85 MW. The primary scientific missions of the HFIR include cold and thermal neutron scattering, materials irradiation, and isotope production. An engineering design study of the conversion of the HFIR from HEU to low-enriched uranium (LEU) fuel is ongoing at the Oak Ridge National Laboratory. The LEU fuel considered is based on a uranium-molybdenum alloy that is 10 percent by weight molybdenum (U-10Mo) with a ${ }^{235} \mathrm{U}$ enrichment of $19.75 \mathrm{wt} \%$. The LEU core design discussed in this report is based on the design documented in ORNL/TM-2010/318. Much of the data reported in Sections 1 and 2 of this document was derived from or taken directly out of ORNL/TM2010/318. The purpose of this report is to document the design parameters for and the anticipated normal operating conditions of the conceptual HFIR LEU fuel to aid in developing requirements for HFIR irradiation experiments.
\end{abstract}





\section{INTRODUCTION}

An engineering design study for a fuel that would enable the conversion of the High Flux Isotope Reactor (HFIR) from high-enriched uranium (HEU) to low-enriched uranium (LEU) is ongoing as part of an effort sponsored by the U.S. Department of Energy's (DOE's) National Nuclear Security Administration through the Global Threat Reduction Initiative/Reduced Enrichment for Research and Test Reactors (RERTR) Program. Given the unique fuel, particular core design, and high power density of HFIR, and the requirement that the impact of the fuel change on the core performance and operation be minimal, this conversion study represents a complex and challenging task.

Irradiation experiments with HFIR LEU fuel test plates will be conducted to observe how these plates behave under irradiation conditions as similar as possible to those they will see in HFIR. Irradiation conditions including fission rate densities, accumulated fission densities, coolant flow, heat fluxes, and temperatures need to be considered for these experiments. The purpose of this report is to document the input parameters required for the conceptual design of HFIR LEU irradiation experiments. The LEU core design discussed in this report is based on the design documented in ORNL/TM-2010/318 [1]. Much of the data reported in Sections 1 and 2 of this document was derived from or taken directly out of ORNL/TM-2010/318.

\subsection{HFIR DESCRIPTION AND CORE DESIGN}

The HEU-fueled HFIR is an 85 MW, very high flux, pressurized, light-water-cooled and moderated, flux-trap type reactor, which is operated at the Oak Ridge National Laboratory (ORNL). The missions of HFIR are currently to support neutron scattering experiments, isotope production, and materials irradiation research. The reactor core consists of a series of concentric annular regions: a central flux trap containing vertical experimental targets surrounded by two fuel elements separated by a thin water region, a region containing two control plates, a beryllium reflector, and a water region to the edge of the pressure vessel, which is located in a pool of water.

The two fuel elements in HFIR are identified as inner fuel element (IFE) and outer fuel element (OFE). They are composed of numerous, involute-shaped fuel plates $1.27 \mathrm{~mm}$ thick, as illustrated in Fig. 1(a). The plates are separated by a water-filled cooling channel $1.27 \mathrm{~mm}$ thick, and are held together by two cylindrical aluminum side walls. The fuel plates have a sandwich-type design with a fuel region enclosed in an aluminium clad, as illustrated in Fig. 1(b).

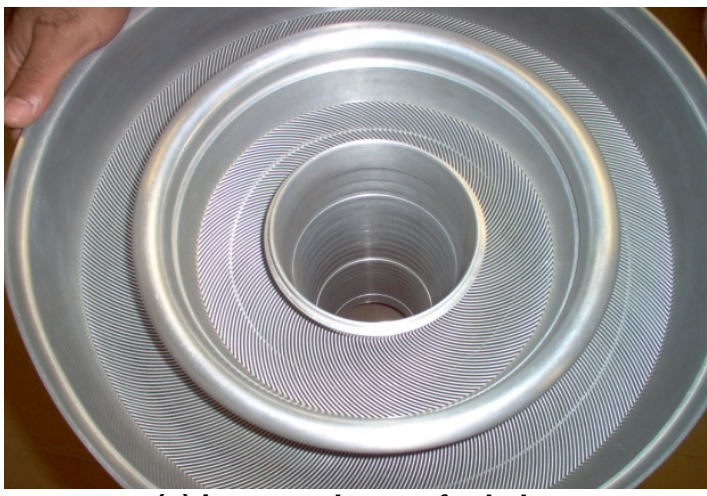

(a) inner and outer fuel elements

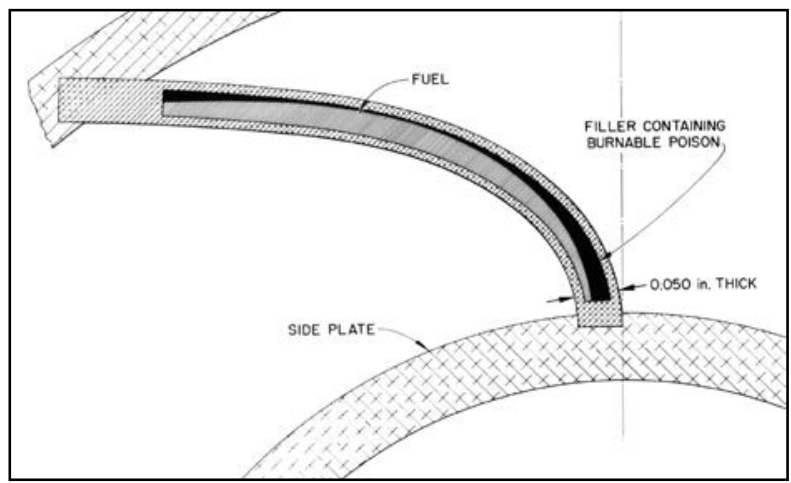

(b) HEU inner fuel plate profile

Fig. 1. HFIR fuel elements. 
The HFIR LEU reference core design is described in detail in ORNL/TM-2010/318 [1] and is summarized here. The LEU fuel material considered is a metallic alloy containing $90 \mathrm{wt} \%$ uranium and $10 \mathrm{wt} \%$ molybdenum. The density of the fuel is $17.02 \mathrm{~g} / \mathrm{cm}^{3}$ and the enrichment is $19.75 \mathrm{wt} \%{ }^{235} \mathrm{U}$ in uranium. The LEU core design consists of ${ }^{235} \mathrm{U}$ and total uranium loads of $25.3 \mathrm{~kg}$ and $127.9 \mathrm{~kg}$, respectively. A thin (0.001 in.) zirconium diffusion barrier layer on the surfaces of the fuel meat region separates the fuel meat from the filler and clad inside the fuel plate. A filler material is located between the $\mathrm{Zr}$ layer and one side of the Al-6061 clad. The filler material is aluminum and the IFE filler contains boron in the form of $\mathrm{B}_{4} \mathrm{C}$. The total amount of ${ }^{10} \mathrm{~B}$ in the IFE filler totals $5.4 \mathrm{~g}$. The LEU core geometry and details are summarized in Table 1.

Table 1. Key parameters of the HFIR LEU conceptual core

\begin{tabular}{|c|c|c|}
\hline \multicolumn{3}{|l|}{ Reactor data } \\
\hline Operating power (MW) & \multicolumn{2}{|c|}{100} \\
\hline Cycle length (days) & \multicolumn{2}{|c|}{26} \\
\hline Number of fuel elements & \multicolumn{2}{|c|}{2} \\
\hline \multicolumn{3}{|l|}{ Fuel data } \\
\hline Type & \multicolumn{2}{|c|}{ U-10Mo } \\
\hline Enrichment (wt \% ${ }^{235} \mathrm{U}$ ) & \multicolumn{2}{|c|}{19.75} \\
\hline Total load ${ }^{235} \mathrm{U}(\mathrm{kg})$ & \multicolumn{2}{|c|}{25.3} \\
\hline Total load uranium (kg) & \multicolumn{2}{|c|}{127.9} \\
\hline Fuel elements data & Inner fuel element & Outer fuel element \\
\hline Load of ${ }^{235} \mathrm{U}(\mathrm{kg})$ & 6.4 & 18.9 \\
\hline Number of fuel plates & 171 & 369 \\
\hline Fuel plate width $(\mathrm{cm})$ & 9.2 & 8.1 \\
\hline Fuel plate thickness (cm) & 0.127 & 0.127 \\
\hline Coolant channel between plates $(\mathrm{cm})$ & 0.127 & 0.127 \\
\hline Fuel plate clad thickness $(\mathrm{cm})$ & 0.0254 & 0.0254 \\
\hline
\end{tabular}

The fuel within the involute fuel plate is graded radially along the arc of the involute to flatten the power profile and is graded axially to reduce the power "spike" at the bottom of the fuel plate to satisfy thermal hydraulics limits. The dimensions characterizing the LEU radial profiles are presented in Table 2 and are illustrated in Fig. 2. The axial grading applied to the bottom $3 \mathrm{~cm}$ of the fuel elements is illustrated in Fig. 3. The axial grading shape, as illustrated in Fig. 3, consists of a flat radial grading on the bottom $1 \mathrm{~cm}$ (75 $\mu \mathrm{m}$ fuel meat thickness), with planes connecting the radially flat profile on the bottom $1 \mathrm{~cm}$ to the radial profile applied above $3 \mathrm{~cm}$ from the bottom.

Table 2. Radial fuel regions in the MCNP model for HFIR LEU

\begin{tabular}{cccccc}
\hline \multicolumn{2}{c}{ Inner fuel element } & & \multicolumn{2}{c}{ Outer fuel element } \\
\cline { 1 - 2 } \cline { 5 - 5 } $\begin{array}{c}\text { Distance along } \\
\text { plate length } \\
(\mathbf{c m})\end{array}$ & $\begin{array}{c}\text { Fuel meat } \\
\text { thickness } \\
(\boldsymbol{\mu m})\end{array}$ & & $\begin{array}{c}\text { Distance along } \\
\text { plate length } \\
(\mathbf{c m})\end{array}$ & $\begin{array}{c}\text { Fuel meat } \\
\text { thickness } \\
(\boldsymbol{\mu m})\end{array}$ \\
\hline 0.231 & 75 & & 0.234 & 216 \\
3.072 & 407 & & 1.667 & 582 \\
6.110 & 407 & & 5.286 & 582 \\
8.027 & 193 & & 7.323 & 158 \\
\hline
\end{tabular}



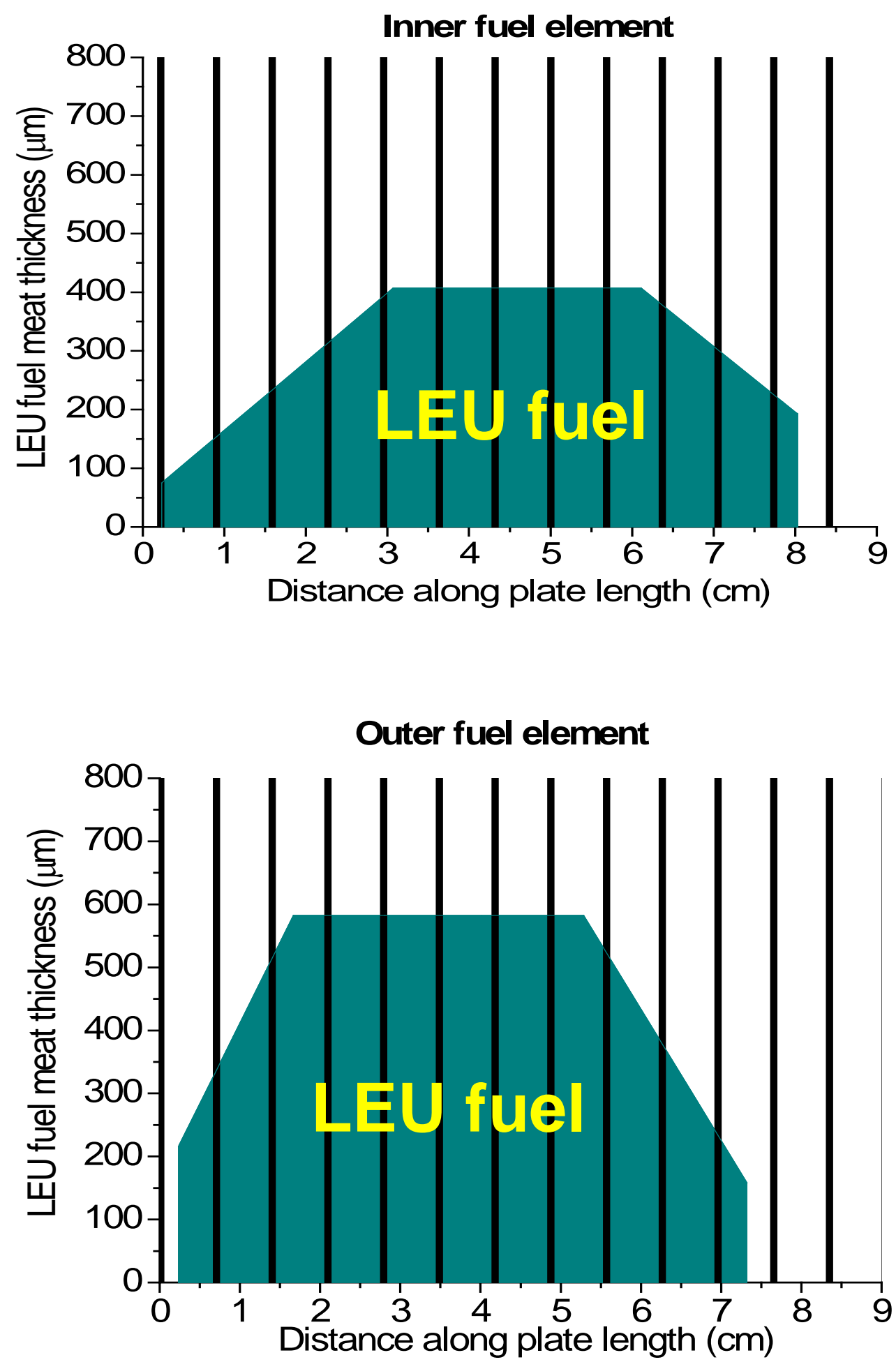

Fig. 2. Radial grading profile for LEU fuel plates. 


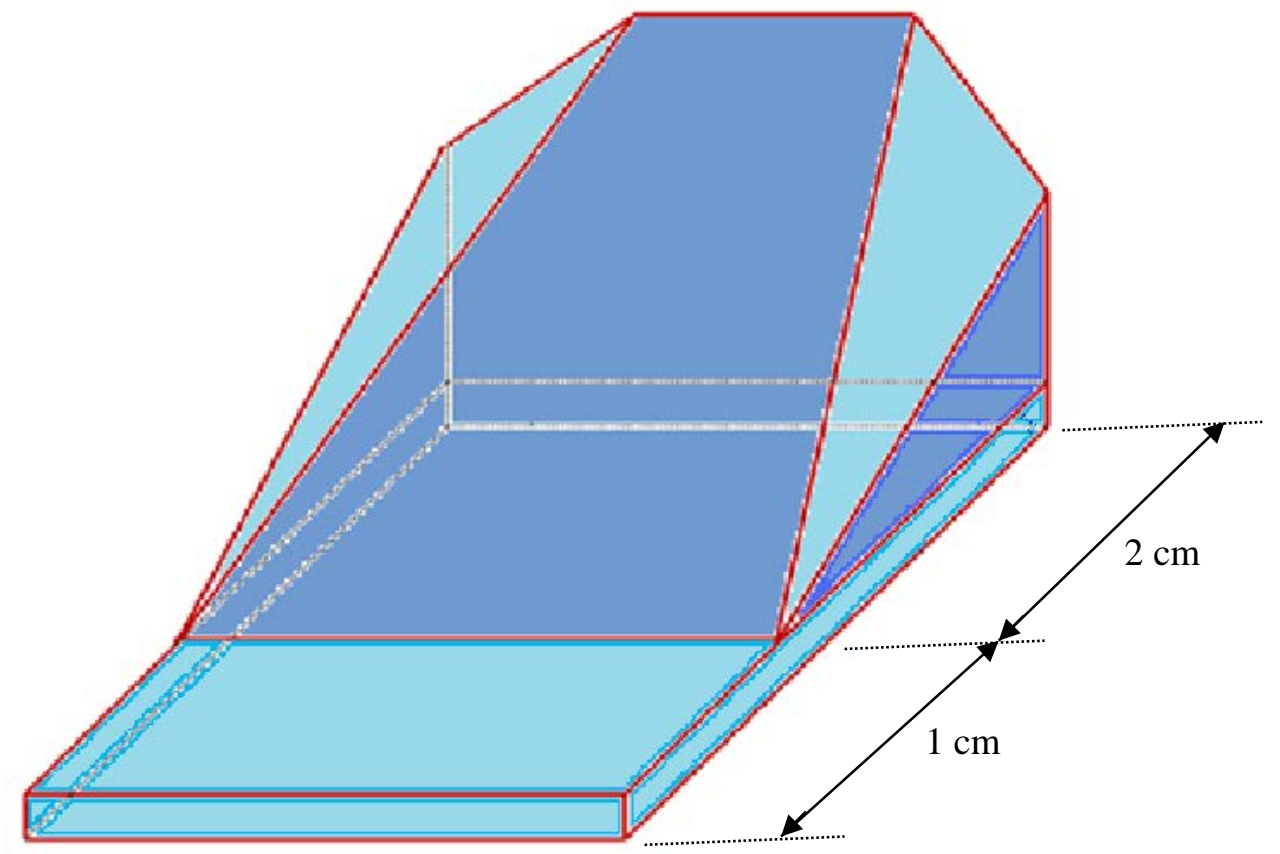

Fig. 3. Axial grading profiles for LEU fuel (0-3 cm from bottom of fuel element). 


\section{NEUTRONICS PARAMETERS}

The set of computational methods and tools used as the basis for HFIR LEU neutronics studies includes the Monte Carlo neutron transport code MCNP [2], the Monte Carlo-based depletion tool VESTA [3], and the nuclear analysis code system SCALE [4]. The MCNP model used for the HFIR LEU configuration is based on the 3-D MCNP revised model for HFIR HEU cycle 400 [5]. The LEU fuel in the IFE and the OFE regions is modeled by homogenizing the fuel meat, $\mathrm{Zr}$ diffusion layer, $\mathrm{Al}$ (and $\mathrm{B}_{4} \mathrm{C}$ in IFE only) filler, and $\mathrm{Al}$ cladding of the fuel plates and the water coolant between the fuel plates. To approximate the variation of the ${ }^{235} \mathrm{U}$ content in the radial direction of the fuel plate (i.e., radial fuel grading), eight radial regions with different ${ }^{235} \mathrm{U}$ concentrations are used in the IFE modeling. A similar model is used for the OFE, but with nine radial regions. The dimensions of the radial fuel regions in the IFE and OFE models are shown in Table 3 and the dimensions for the axial layers are shown in Table 4.

Table 3. Radial fuel regions in the MCNP model for HFIR LEU

\begin{tabular}{cccccc}
\hline \multicolumn{2}{c}{$\begin{array}{c}\text { Inner fuel element } \\
\text { IFE }\end{array}$} & & \multicolumn{2}{c}{$\begin{array}{c}\text { Outer fuel element } \\
\text { OFE }\end{array}$} \\
\cline { 1 - 2 } \cline { 5 - 5 } Region \# & $\begin{array}{c}\text { Outer radius } \\
(\mathbf{c m})\end{array}$ & & Region \# & $\begin{array}{c}\text { Outer radius } \\
(\mathbf{c m})\end{array}$ \\
\cline { 5 - 6 } $1^{a}$ & 7.50 & & 1 & 15.16 \\
2 & 8.50 & & 2 & 15.50 \\
3 & 9.50 & & 3 & 16.50 \\
4 & 10.50 & & 4 & 17.50 \\
5 & 11.50 & & 5 & 18.50 \\
6 & 12.50 & & 6 & 19.50 \\
7 & 12.59 & & 7 & 20.50 \\
8 & 12.60 & & 8 & 20.99 \\
& & & 9 & 21.00 \\
\hline
\end{tabular}

${ }^{a}$ Inner radii are $7.14 \mathrm{~cm}$ and $15.15 \mathrm{~cm}$ for IFE and OFE, respectively.

Table 4. Axial fuel regions in the MCNP model for HFIR LEU

\begin{tabular}{cccccc}
\hline Region \# & $\begin{array}{c}\text { Top edge } \\
\text { location } \\
(\mathbf{c m})^{\boldsymbol{a}}\end{array}$ & $\begin{array}{c}\text { Thickness } \\
\mathbf{( c m )}\end{array}$ & Region \# & $\begin{array}{c}\text { Top edge } \\
\text { location } \\
(\mathbf{c m})^{\boldsymbol{a}}\end{array}$ & $\begin{array}{c}\text { Thickness } \\
(\mathbf{c m})\end{array}$ \\
\hline 1 & 25.4 & 0.5 & 11 & -1.0 & 3.2 \\
2 & 24.9 & 0.5 & 12 & -4.2 & 8.4 \\
3 & 24.4 & 1.0 & 13 & -12.6 & 4.2 \\
4 & 23.4 & 1.0 & 14 & -16.8 & 4.2 \\
5 & 22.4 & 1.4 & 15 & -21.0 & 1.4 \\
6 & 21.0 & 4.2 & 16 & -22.4 & 1.0 \\
7 & 16.8 & 4.2 & 17 & -23.4 & 1.0 \\
8 & 12.6 & 8.4 & 18 & -24.4 & 0.5 \\
9 & 4.2 & 3.2 & 19 & -24.9 & 0.5 \\
10 & 1.0 & 2.0 & & & \\
\hline
\end{tabular}

${ }^{a}$ Location is with respect to the core midline (at axial location $0.0 \mathrm{~cm}$ ). 


\section{$2.1 \quad$ FISSION RATES AND DENSITIES}

Fission rate data were calculated for each of the defined regions in the two fuel elements based on flux and fission density tallies in MCNP for BOC, EOC, and at selected intermediate times during the irradiation cycle. These data were used to calculate the accumulated fission densities for each of the fuel regions. Relative fission density data for the LEU core at days 0 (BOC), 1, 5, 10, 15, 20, 23 and 26 (EOC) are listed and illustrated in ORNL/TM-2010/318 [1]. The fission rate densities and fission densities are provided on a per $\mathrm{cm}^{3} \mathrm{U}$-Mo basis and were calculated assuming a total core power of 100 MW and 200.7 MeV/fission.

The maximum fission rate densities (fissions/ $\mathrm{cm}^{3} \mathrm{UMo}-\mathrm{s}$ ) for the defined fuel regions in the IFE and OFE for BOC, EOC, and at selected intermediate times during the cycle are listed in Table 5. The maximum local fission rate density at any time in the irradiation cycle is $2.25 \times 10^{15}$ fissions $/ \mathrm{cm}^{3} \mathrm{UMo}-\mathrm{s}$, and this occurs at BOC in the fuel region located at the innermost radial edge of the IFE at the core horizontal midplane. The fission rate density data for the LEU core at BOC and EOC are listed in Tables 6 and 7, respectively. Graphical representations of the fission rate densities are provided for BOC, day 1 (after build-in of Xe), day 15 (middle-of-cycle conditions), and EOC in Fig. 4. Radial and axial profiles of the fission rate densities are provided in Figs. 5 and 6, respectively, for both BOC and EOC. Based on Figs. 5 and 6, it is recommended that a minimum irradiation sample fission rate density of 1.3 $\mathrm{x} 10^{15}$ fissions $/ \mathrm{cm}^{3} \mathrm{UMo}$-s be used to represent the inner element and a minimum of $1.0 \times 10^{15}$ fissions $/ \mathrm{cm}^{3} \mathrm{UMo}-\mathrm{s}$ be used to represent the outer element.

A peak local EOC accumulated (i.e., discharged) fission density of $4.13 \times 10^{21}$ fissions $/ \mathrm{cm}^{3} \mathrm{UMo}$ takes place at the innermost edge of the IFE at the core horizontal midplane. The IFE and OFE average discharged fission densities are $1.17 \times 10^{21}$ and $7.25 \times 10^{20}$ fissions $/ \mathrm{cm}^{3} \mathrm{UMo}$, respectively. The local accumulated fission densities for each of the defined fuel regions are listed in Table 8 and are illustrated graphically in Fig. 7. Radial and axial profiles of the fission density data are provided in Figs. 8 and 9 , respectively. Based on Figs. 8 and 9, it is recommended that a minimum irradiation sample accumulated fission density of $3.25 \times 10^{21}$ fissions $/ \mathrm{cm}^{3} \mathrm{UMo}$ be used for the inner element and $2.25 \times 10^{21}$ fissions $/ \mathrm{cm}^{3} \mathrm{UMo}$ be used for the outer element.

Table 5. Maximum fission rate density during cycle and accumulated fission density

\begin{tabular}{cccc}
\hline Day & Units & IFE & OFE \\
\hline 0 & fissions $/ \mathrm{cm}^{3} \mathrm{UMo}-\mathrm{s}$ & $2.247 \mathrm{E}+15$ & $1.359 \mathrm{E}+15$ \\
1 & fissions $/ \mathrm{cm}^{3} \mathrm{UMo}-\mathrm{s}$ & $2.129 \mathrm{E}+15$ & $1.466 \mathrm{E}+15$ \\
5 & fissions $/ \mathrm{cm}^{3} \mathrm{UMo}-\mathrm{s}$ & $2.073 \mathrm{E}+15$ & $1.396 \mathrm{E}+15$ \\
10 & fissions $/ \mathrm{cm}^{3} \mathrm{UMo}-\mathrm{s}$ & $1.973 \mathrm{E}+15$ & $1.322 \mathrm{E}+15$ \\
15 & fissions $/ \mathrm{cm}^{3} \mathrm{UMo}-\mathrm{s}$ & $1.812 \mathrm{E}+15$ & $1.250 \mathrm{E}+15$ \\
20 & fissions $/ \mathrm{cm}^{3} \mathrm{UMo}-\mathrm{s}$ & $1.621 \mathrm{E}+15$ & $1.191 \mathrm{E}+15$ \\
23 & fissions $/ \mathrm{cm}^{3} \mathrm{UMo}-\mathrm{s}$ & $1.507 \mathrm{E}+15$ & $1.150 \mathrm{E}+15$ \\
26 & fissions $/ \mathrm{cm}^{3} \mathrm{UMo}-\mathrm{s}$ & $1.409 \mathrm{E}+15$ & $1.115 \mathrm{E}+15$ \\
\hline 26 & fissions $/ \mathrm{cm}^{3} \mathrm{UMo}$ & $4.131 \mathrm{E}+21$ & $2.884 \mathrm{E}+21$ \\
\hline
\end{tabular}


Table 6. Fission rate density $\left(\mathrm{x}^{10}{ }^{15}\right.$ fissions $\left./ \mathrm{cm}^{3} \mathrm{UMo}-\mathrm{s}\right)$ for HFIR LEU at BOC

\begin{tabular}{|c|c|c|c|c|c|c|c|c|c|c|c|c|c|c|c|c|c|}
\hline \multirow{2}{*}{$\begin{array}{c}\text { Axial } \\
\text { region \# }\end{array}$} & \multicolumn{8}{|c|}{ IFE } & \multicolumn{9}{|c|}{ OFE } \\
\hline & $\mathrm{r}=1^{a}$ & $r=2$ & $\mathbf{r}=3$ & $r=4$ & $r=5$ & $r=6$ & $\mathbf{r}=7$ & $r=8$ & $r=1$ & $r=2$ & $\mathbf{r}=3$ & $r=4$ & $r=5$ & $r=6$ & $r=7$ & $\mathbf{r}=\mathbf{8}$ & $\mathbf{r}=9$ \\
\hline 1 & 1.584 & 1.086 & 0.733 & 0.594 & 0.565 & 0.669 & 0.866 & 0.914 & 0.867 & 0.730 & 0.483 & 0.354 & 0.308 & 0.277 & 0.277 & 0.314 & 0.341 \\
\hline 2 & 1.364 & 0.822 & 0.479 & 0.364 & 0.359 & 0.491 & 0.721 & 0.781 & 0.727 & 0.588 & 0.331 & 0.212 & 0.180 & 0.168 & 0.187 & 0.247 & 0.289 \\
\hline 3 & 1.257 & 0.704 & 0.375 & 0.278 & 0.281 & 0.412 & 0.633 & 0.679 & 0.634 & 0.506 & 0.278 & 0.169 & 0.141 & 0.134 & 0.155 & 0.215 & 0.258 \\
\hline 4 & 1.214 & 0.668 & 0.348 & 0.259 & 0.264 & 0.389 & 0.591 & 0.630 & 0.584 & 0.471 & 0.264 & 0.163 & 0.136 & 0.130 & 0.152 & 0.211 & 0.253 \\
\hline 5 & 1.235 & 0.685 & 0.361 & 0.270 & 0.276 & 0.397 & 0.589 & 0.630 & 0.576 & 0.469 & 0.272 & 0.173 & 0.145 & 0.139 & 0.164 & 0.227 & 0.265 \\
\hline 6 & 1.417 & 0.788 & 0.422 & 0.319 & 0.324 & 0.455 & 0.658 & 0.700 & 0.644 & 0.533 & 0.317 & 0.207 & 0.176 & 0.173 & 0.216 & 0.328 & 0.400 \\
\hline 7 & 1.726 & 0.963 & 0.516 & 0.392 & 0.398 & 0.556 & 0.799 & 0.852 & 0.779 & 0.647 & 0.390 & 0.257 & 0.221 & 0.223 & 0.299 & 0.489 & 0.609 \\
\hline 8 & 2.068 & 1.155 & 0.620 & 0.472 & 0.480 & 0.672 & 0.967 & 1.028 & 0.943 & 0.784 & 0.476 & 0.318 & 0.278 & 0.287 & 0.409 & 0.718 & 0.918 \\
\hline 9 & 2.240 & 1.250 & 0.672 & 0.512 & 0.523 & 0.732 & 1.052 & 1.118 & 1.033 & 0.857 & 0.522 & 0.351 & 0.311 & 0.332 & 0.516 & 0.993 & 1.308 \\
\hline 10 & 2.247 & 1.254 & 0.675 & 0.514 & 0.524 & 0.735 & 1.058 & 1.127 & 1.039 & 0.864 & 0.524 & 0.353 & 0.313 & 0.337 & 0.528 & 1.028 & 1.359 \\
\hline 11 & 2.212 & 1.233 & 0.665 & 0.507 & 0.517 & 0.723 & 1.038 & 1.106 & 1.020 & 0.847 & 0.515 & 0.347 & 0.309 & 0.330 & 0.515 & 0.997 & 1.314 \\
\hline 12 & 2.001 & 1.116 & 0.600 & 0.457 & 0.465 & 0.649 & 0.933 & 0.995 & 0.911 & 0.757 & 0.459 & 0.305 & 0.266 & 0.274 & 0.386 & 0.666 & 0.845 \\
\hline 13 & 1.625 & 0.904 & 0.484 & 0.366 & 0.372 & 0.519 & 0.746 & 0.796 & 0.729 & 0.604 & 0.363 & 0.240 & 0.207 & 0.206 & 0.271 & 0.435 & 0.539 \\
\hline 14 & 1.316 & 0.729 & 0.386 & 0.292 & 0.296 & 0.419 & 0.609 & 0.650 & 0.596 & 0.491 & 0.290 & 0.187 & 0.158 & 0.153 & 0.185 & 0.267 & 0.319 \\
\hline 15 & 1.152 & 0.636 & 0.334 & 0.253 & 0.259 & 0.377 & 0.564 & 0.605 & 0.558 & 0.453 & 0.259 & 0.162 & 0.134 & 0.125 & 0.134 & 0.161 & 0.179 \\
\hline 16 & 1.135 & 0.645 & 0.366 & 0.285 & 0.291 & 0.419 & 0.612 & 0.652 & 0.615 & 0.510 & 0.304 & 0.195 & 0.164 & 0.148 & 0.150 & 0.169 & 0.184 \\
\hline 17 & 1.219 & 0.766 & 0.525 & 0.445 & 0.443 & 0.560 & 0.739 & 0.777 & 0.760 & 0.659 & 0.469 & 0.349 & 0.294 & 0.257 & 0.228 & 0.215 & 0.219 \\
\hline 18 & 1.377 & 0.988 & 0.763 & 0.676 & 0.661 & 0.744 & 0.893 & 0.934 & 0.937 & 0.856 & 0.699 & 0.569 & 0.488 & 0.416 & 0.343 & 0.289 & 0.271 \\
\hline 19 & 1.587 & 1.248 & 1.027 & 0.924 & 0.887 & 0.928 & 1.038 & 1.058 & 1.065 & 1.003 & 0.870 & 0.744 & 0.645 & 0.546 & 0.438 & 0.347 & 0.314 \\
\hline
\end{tabular}

${ }^{a} \mathrm{r}=\mathrm{n}$ denotes the radial region number; $\mathrm{n}$ varies from 1 to 8 for the IFE and from 1 to 9 for the OFE. 
Table 7. Fission rate density $\left({\mathrm{x} 10^{15}}^{15}\right.$ fissions $\left./ \mathrm{cm}^{3} \mathrm{UMo}-\mathrm{s}\right)$ for HFIR LEU at EOC

\begin{tabular}{|c|c|c|c|c|c|c|c|c|c|c|c|c|c|c|c|c|c|}
\hline \multirow{2}{*}{$\begin{array}{c}\text { Axial } \\
\text { region \# }\end{array}$} & \multicolumn{8}{|c|}{ IFE } & \multicolumn{9}{|c|}{ OFE } \\
\hline & $r=1$ & $r=2$ & $\mathbf{r}=3$ & $r=4$ & $r=5$ & $r=6$ & $\mathbf{r}=7$ & $\mathbf{r}=\mathbf{8}$ & $r=1$ & $r=2$ & $\mathbf{r}=3$ & $r=4$ & $r=5$ & $r=6$ & $r=7$ & $r=8$ & $\mathbf{r}=\mathbf{9}$ \\
\hline 1 & 1.171 & 0.962 & 0.703 & 0.572 & 0.549 & 0.638 & 0.778 & 0.825 & 0.784 & 0.669 & 0.485 & 0.377 & 0.350 & 0.353 & 0.437 & 0.634 & 0.770 \\
\hline 2 & 1.112 & 0.831 & 0.511 & 0.377 & 0.369 & 0.494 & 0.677 & 0.732 & 0.687 & 0.559 & 0.341 & 0.228 & 0.205 & 0.215 & 0.316 & 0.564 & 0.734 \\
\hline 3 & 1.064 & 0.735 & 0.407 & 0.287 & 0.286 & 0.416 & 0.603 & 0.655 & 0.608 & 0.486 & 0.280 & 0.177 & 0.157 & 0.170 & 0.278 & 0.547 & 0.731 \\
\hline 4 & 1.047 & 0.701 & 0.372 & 0.260 & 0.262 & 0.385 & 0.560 & 0.613 & 0.566 & 0.450 & 0.262 & 0.167 & 0.149 & 0.165 & 0.278 & 0.564 & 0.760 \\
\hline 5 & 1.069 & 0.714 & 0.380 & 0.268 & 0.269 & 0.386 & 0.552 & 0.603 & 0.557 & 0.443 & 0.267 & 0.175 & 0.157 & 0.174 & 0.296 & 0.600 & 0.808 \\
\hline 6 & 1.157 & 0.798 & 0.436 & 0.309 & 0.309 & 0.430 & 0.602 & 0.662 & 0.609 & 0.486 & 0.302 & 0.204 & 0.183 & 0.203 & 0.343 & 0.676 & 0.904 \\
\hline 7 & 1.288 & 0.932 & 0.523 & 0.369 & 0.367 & 0.504 & 0.696 & 0.769 & 0.709 & 0.563 & 0.356 & 0.242 & 0.218 & 0.242 & 0.405 & 0.760 & 0.996 \\
\hline 8 & 1.380 & 1.056 & 0.610 & 0.431 & 0.426 & 0.580 & 0.791 & 0.884 & 0.811 & 0.640 & 0.410 & 0.280 & 0.252 & 0.281 & 0.466 & 0.836 & 1.076 \\
\hline 9 & 1.405 & 1.105 & 0.651 & 0.460 & 0.454 & 0.616 & 0.836 & 0.935 & 0.858 & 0.675 & 0.435 & 0.297 & 0.268 & 0.299 & 0.493 & 0.870 & 1.114 \\
\hline 10 & 1.409 & 1.111 & 0.656 & 0.462 & 0.457 & 0.618 & 0.836 & 0.936 & 0.858 & 0.678 & 0.437 & 0.298 & 0.269 & 0.299 & 0.495 & 0.870 & 1.115 \\
\hline 11 & 1.401 & 1.100 & 0.649 & 0.458 & 0.452 & 0.612 & 0.832 & 0.930 & 0.853 & 0.673 & 0.433 & 0.296 & 0.267 & 0.297 & 0.491 & 0.866 & 1.110 \\
\hline 12 & 1.356 & 1.037 & 0.600 & 0.424 & 0.419 & 0.570 & 0.777 & 0.868 & 0.797 & 0.628 & 0.403 & 0.275 & 0.248 & 0.276 & 0.458 & 0.825 & 1.063 \\
\hline 13 & 1.248 & 0.900 & 0.504 & 0.357 & 0.355 & 0.487 & 0.673 & 0.746 & 0.686 & 0.544 & 0.343 & 0.233 & 0.211 & 0.235 & 0.394 & 0.744 & 0.975 \\
\hline 14 & 1.127 & 0.771 & 0.417 & 0.295 & 0.295 & 0.414 & 0.584 & 0.645 & 0.594 & 0.473 & 0.291 & 0.195 & 0.175 & 0.195 & 0.333 & 0.664 & 0.889 \\
\hline 15 & 1.058 & 0.707 & 0.380 & 0.270 & 0.273 & 0.396 & 0.576 & 0.630 & 0.581 & 0.462 & 0.275 & 0.178 & 0.159 & 0.176 & 0.301 & 0.610 & 0.823 \\
\hline 16 & 1.064 & 0.742 & 0.441 & 0.330 & 0.333 & 0.465 & 0.640 & 0.692 & 0.644 & 0.528 & 0.335 & 0.226 & 0.203 & 0.219 & 0.339 & 0.623 & 0.814 \\
\hline 17 & 1.131 & 0.886 & 0.657 & 0.554 & 0.543 & 0.643 & 0.782 & 0.826 & 0.774 & 0.677 & 0.517 & 0.416 & 0.385 & 0.396 & 0.491 & 0.700 & 0.845 \\
\hline 18 & 1.207 & 1.060 & 0.897 & 0.810 & 0.783 & 0.831 & 0.914 & 0.947 & 0.899 & 0.833 & 0.726 & 0.649 & 0.616 & 0.616 & 0.674 & 0.798 & 0.893 \\
\hline 19 & 1.259 & 1.164 & 1.046 & 0.978 & 0.940 & 0.955 & 1.000 & 1.017 & 0.980 & 0.930 & 0.858 & 0.802 & 0.769 & 0.761 & 0.788 & 0.856 & 0.912 \\
\hline
\end{tabular}

${ }^{a} \mathrm{r}=\mathrm{n}$ denotes the radial region number; $\mathrm{n}$ varies from 1 to 8 for the IFE and from 1 to 9 for the OFE. 

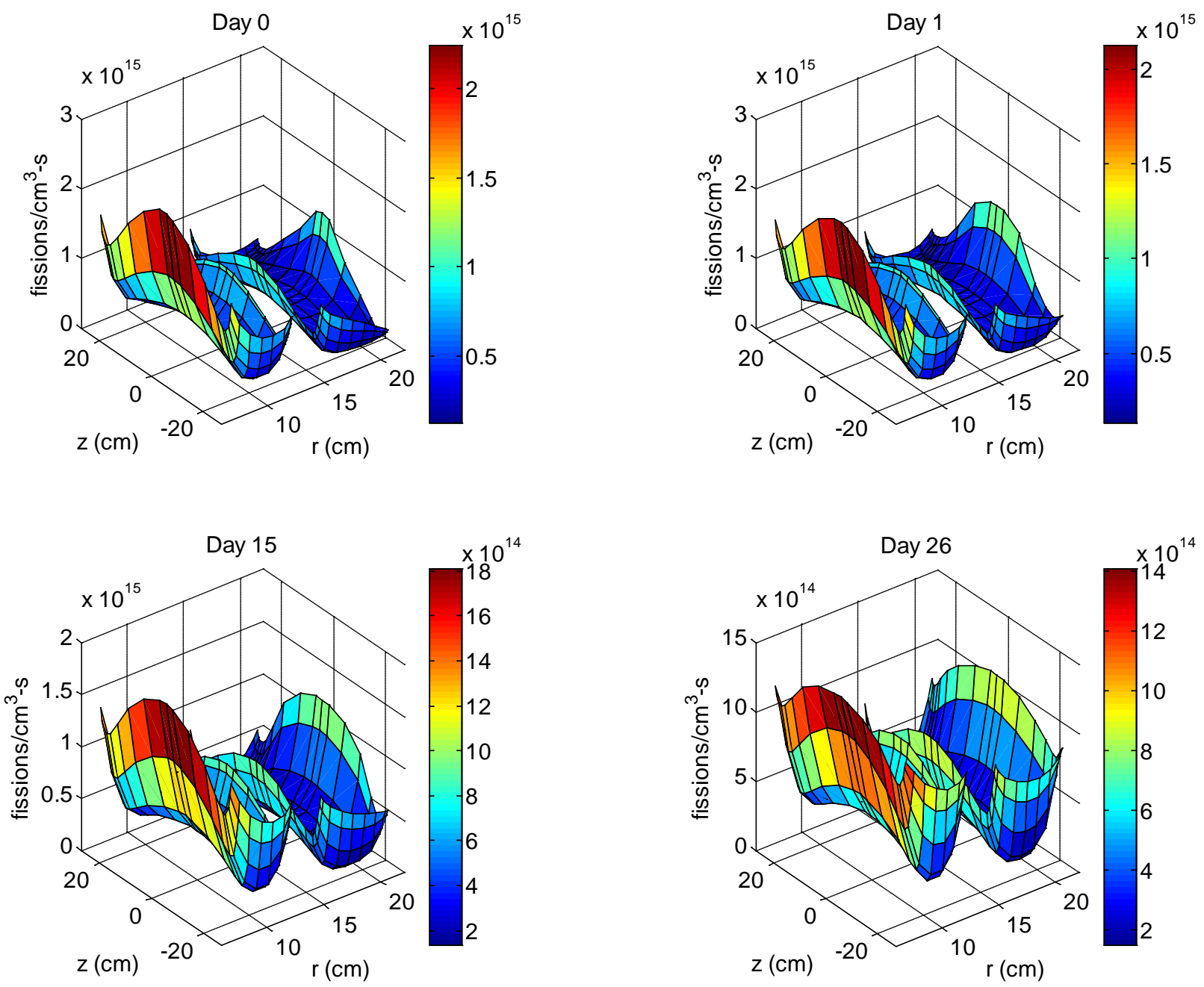

Fig. 4. Graphical representation of LEU fission rate density (fissions $/ \mathrm{cm}^{3} \mathrm{UMo}-\mathrm{s}$ ) at selected times. 

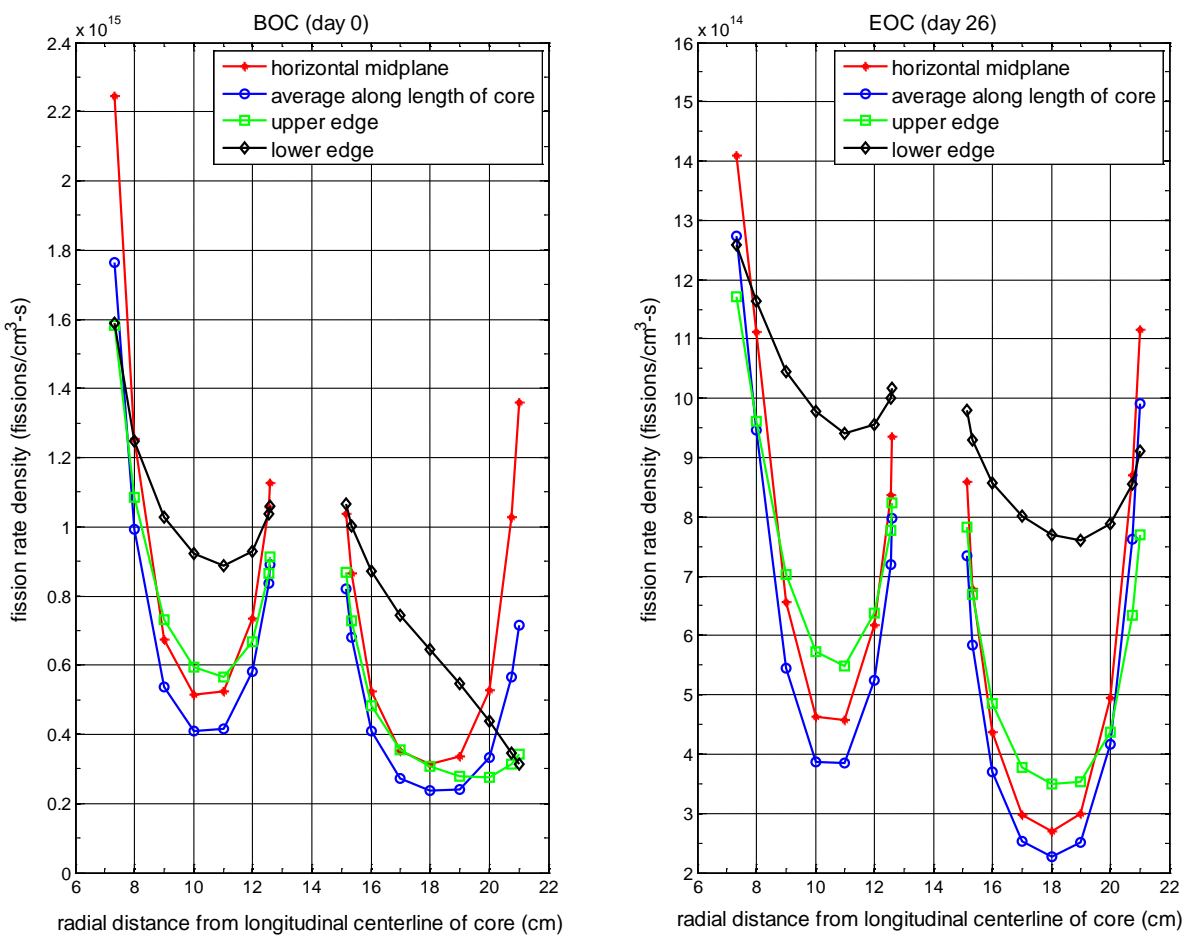

Fig. 5. BOC (left) and EOC (right) fission rate density (fissions $/ \mathrm{cm}^{3} \mathrm{UMo}-\mathrm{s}$ ) radial profiles.
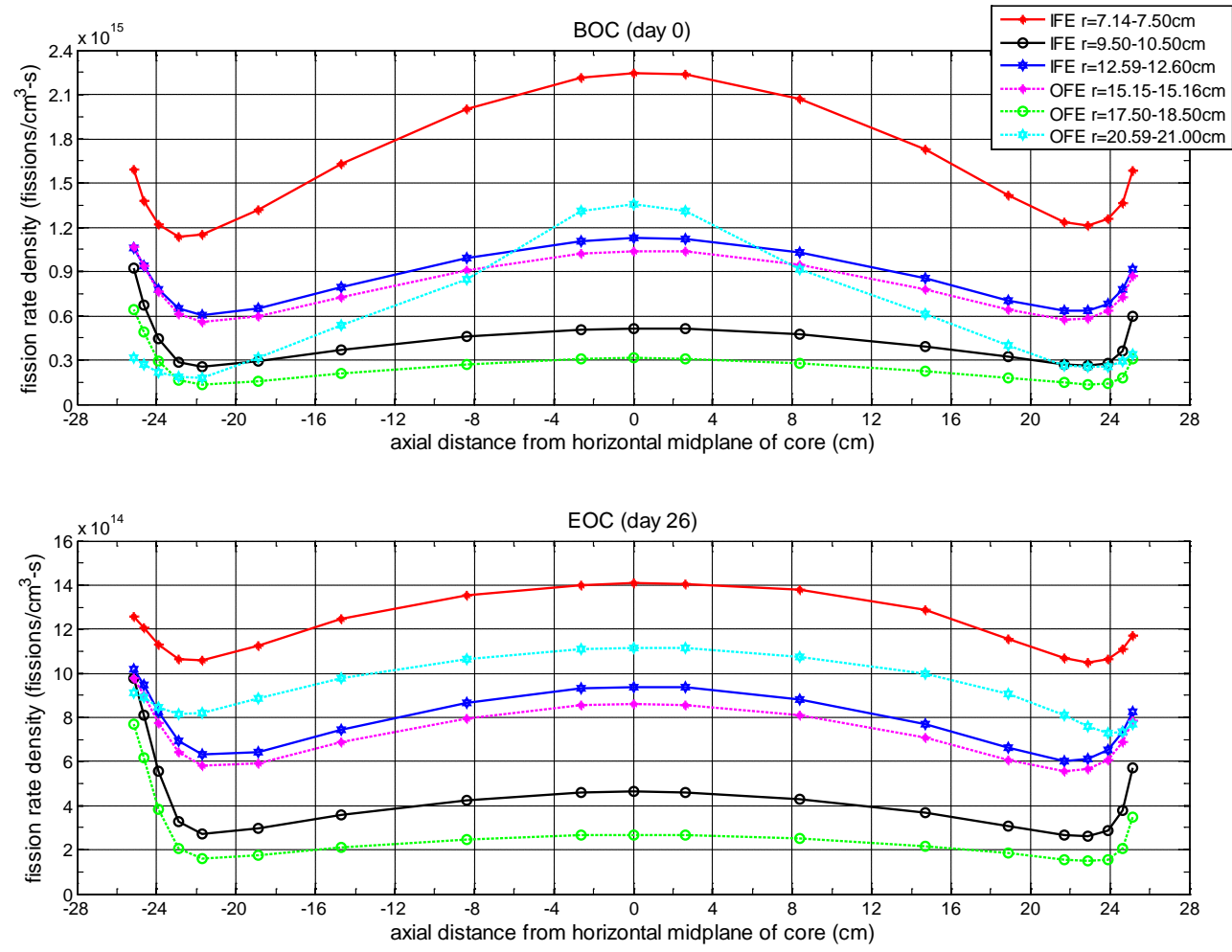

Fig. 6. BOC (top) and EOC (bottom) fission rate density (fissions $/ \mathrm{cm}^{3} \mathrm{UMo}$-s) axial profiles. 
Table 8. Accumulated fission density $\left({\mathrm{x} 10^{21}}^{21}\right.$ fissions $\left./ \mathrm{cm}^{3} \mathrm{UMo}\right)$ for HFIR LEU at EOC

\begin{tabular}{|c|c|c|c|c|c|c|c|c|c|c|c|c|c|c|c|c|c|}
\hline \multirow{2}{*}{$\begin{array}{l}\text { Axial } \\
\text { region \# }\end{array}$} & \multicolumn{8}{|c|}{ IFE } & \multicolumn{9}{|c|}{ OFE } \\
\hline & $r=1$ & $\mathrm{r}=2$ & $r=3$ & $r=4$ & $r=5$ & $r=6$ & $\mathrm{r}=7$ & $r=8$ & $r=1$ & $r=2$ & $r=3$ & $r=4$ & $r=5$ & $r=6$ & $r=7$ & $r=8$ & $r=9$ \\
\hline 1 & 3.072 & 279 & & 269 & & 424 & 1.791 & & 793 & 1.523 & .054 & .796 & & 0.692 & .790 & 1.058 & 1.242 \\
\hline 2 & 2.779 & 834 & 74 & 0.802 & 783 & 1.067 & & & & 1.242 & 727 & 477 & & & .551 & .891 & \\
\hline 3 & 596 & 593 & 846 & 0.608 & 609 & 0.896 & 349 & 461 & 352 & 1.078 & 601 & 374 & 323 & .332 & .472 & 833 & .079 \\
\hline 4 & 532 & 514 & 779 & 0.558 & 566 & 0.834 & 1.249 & 354 & 249 & 0.999 & 567 & 358 & 311 & 323 & 470 & 847 & 107 \\
\hline 5 & 2.585 & 1.548 & 0.803 & 0.580 & 0.586 & 0.847 & 1.240 & 1.342 & 1.233 & 0.996 & 584 & 379 & 331 & 345 & .507 & 918 & 1.200 \\
\hline 6 & 2.892 & 1.767 & 0.933 & 0.680 & 0.685 & 0.963 & 1.378 & 1.491 & 1.366 & 1.111 & 0.673 & 449 & 396 & .418 & 632 & & 1.526 \\
\hline 7 & & 128 & 137 & 825 & & 1.156 & 1.636 & & 626 & 1.321 & 312 & 548 & & 528 & 840 & 597 & 2.100 \\
\hline 8 & 996 & 502 & 353 & 981 & & & 1.923 & 2.092 & 919 & 556 & 965 & 654 & & 644 & 054 & .020 & 2.651 \\
\hline 9 & 115 & 2.679 & 1.460 & 1.057 & 061 & 1.469 & 2.062 & 2.246 & 2.060 & 1.669 & .038 & 705 & 634 & 697 & 148 & .190 & 2.867 \\
\hline 10 & 4.131 & 2.696 & 1.468 & 1.063 & 1.067 & 1.478 & 2.073 & 2.2 & 2.070 & 1.677 & 045 & & & & & & 2.884 \\
\hline 11 & & 2.664 & & 1.051 & & 1.461 & & & & 1.661 & 033 & 702 & 631 & & 144 & 183 & 2.858 \\
\hline 12 & 320 & 2.456 & 329 & 0.963 & 66 & 341 & 1.888 & 2.055 & 885 & 1.528 & 948 & 642 & .577 & 633 & .041 & 2.002 & 2.629 \\
\hline 13 & 278 & 2.051 & 1.094 & 0.794 & 0.799 & 1.112 & 1.576 & 1.711 & 1.569 & 1.274 & 0.783 & 0.528 & 0.472 & & 0.818 & .565 & 2.062 \\
\hline 14 & 2.790 & 1.694 & 0.889 & 0.644 & 0.650 & 0.921 & 1.328 & 1.438 & 1.322 & 1.070 & 0.643 & 0.425 & 0.375 & 0.397 & 0.600 & 1.105 & 1.446 \\
\hline 15 & & & & 0.573 & & & & & & & & & & & .494 & 881 & 1.144 \\
\hline 16 & & 1.564 & 0.896 & 0.676 & & 0.979 & 1.400 & 1.504 & 1.410 & 1.154 & 0.704 & & 0.409 & & 0.549 & 0.886 & 1.111 \\
\hline 17 & 2.705 & 1.890 & 1.328 & 1.113 & 1.103 & 1.353 & 1.715 & 1.801 & 1.713 & 1.497 & 1.100 & 0.854 & 0.763 & 0.736 & 0.814 & 1.029 & 1.189 \\
\hline 18 & 3.008 & 2.379 & 1.901 & 1.687 & 1.637 & 1.795 & 2.057 & 2.123 & 2.056 & 1.900 & 1.600 & 1.374 & 1.253 & 1.178 & 1.168 & 1.241 & 1.323 \\
\hline 19 & 3.299 & 2.799 & 2.386 & 2.174 & 2.089 & 2.153 & 2.324 & 2.377 & 2.304 & 2.182 & 1.956 & 1.759 & 1.619 & 1.508 & 1.425 & 1.400 & 1.426 \\
\hline
\end{tabular}

${ }^{a} \mathrm{r}=\mathrm{n}$ denotes the radial region number; $\mathrm{n}$ varies from 1 to 8 for the IFE and from 1 to 9 for the OFE. 


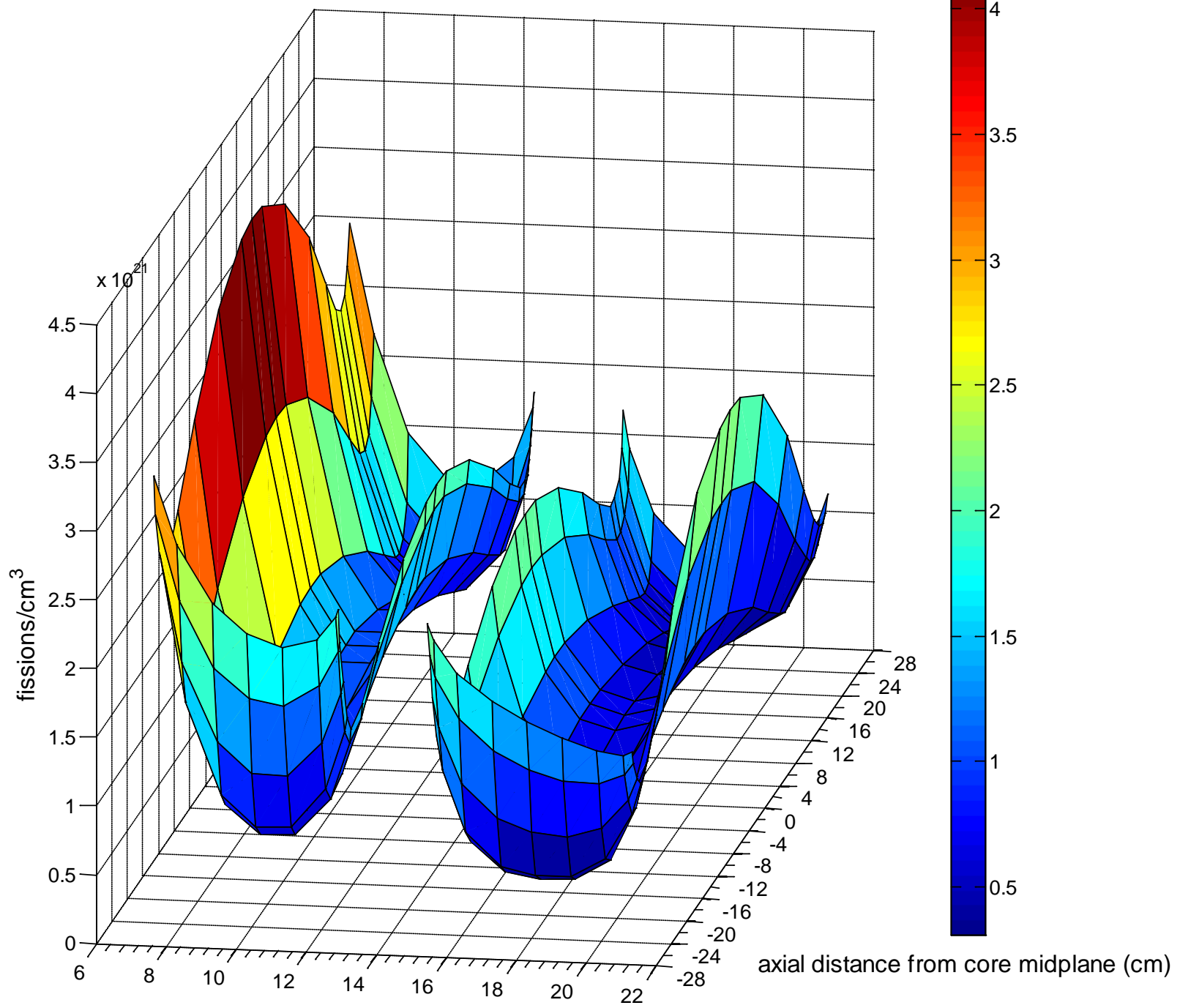

radial distance from core centerline $(\mathrm{cm})$

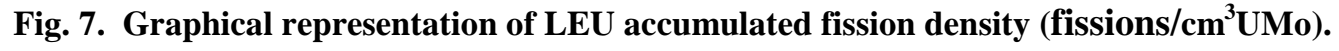




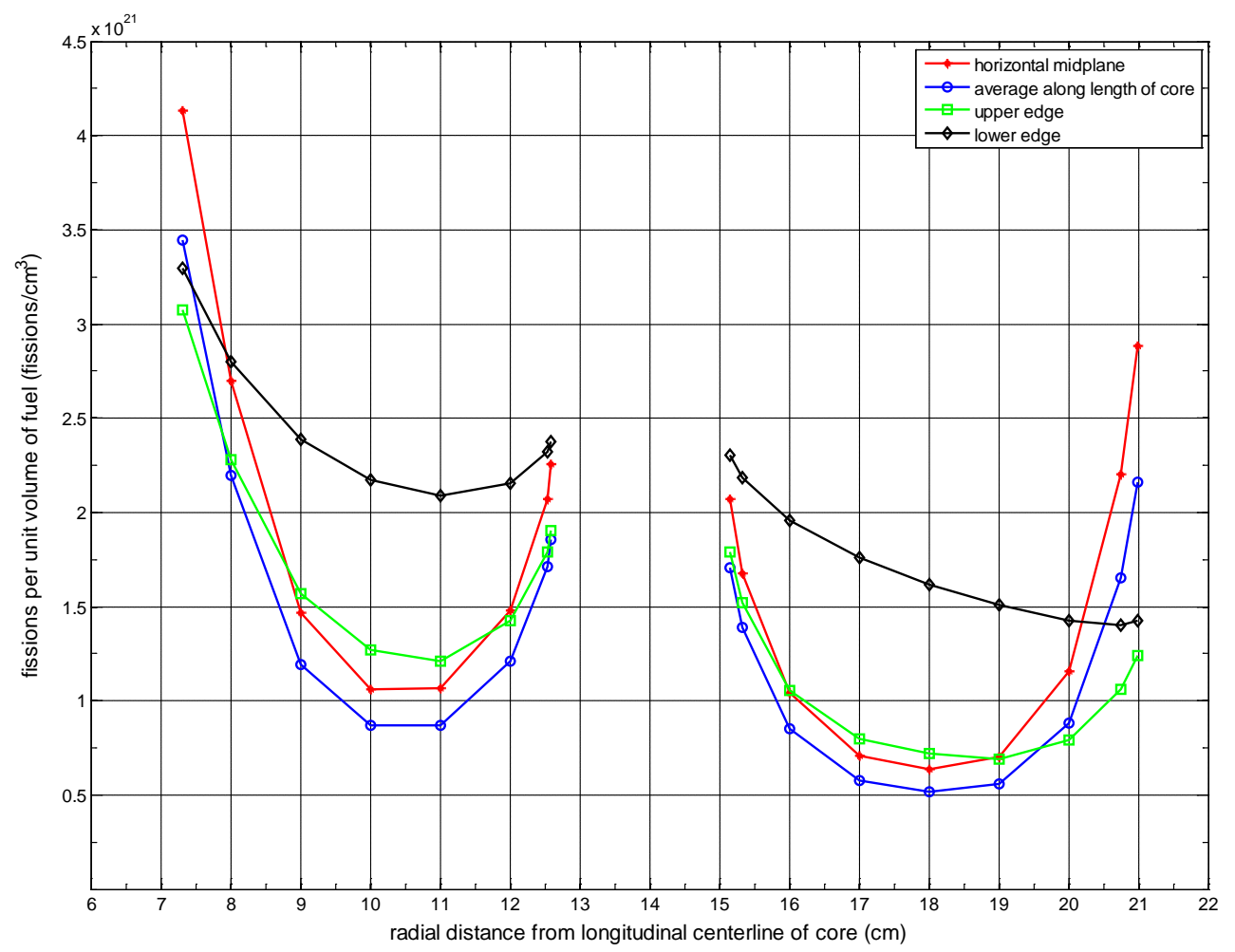

Fig. 8. Accumulated fission density (fissions $/ \mathrm{cm}^{3} \mathrm{UMo}$ ) radial profiles.

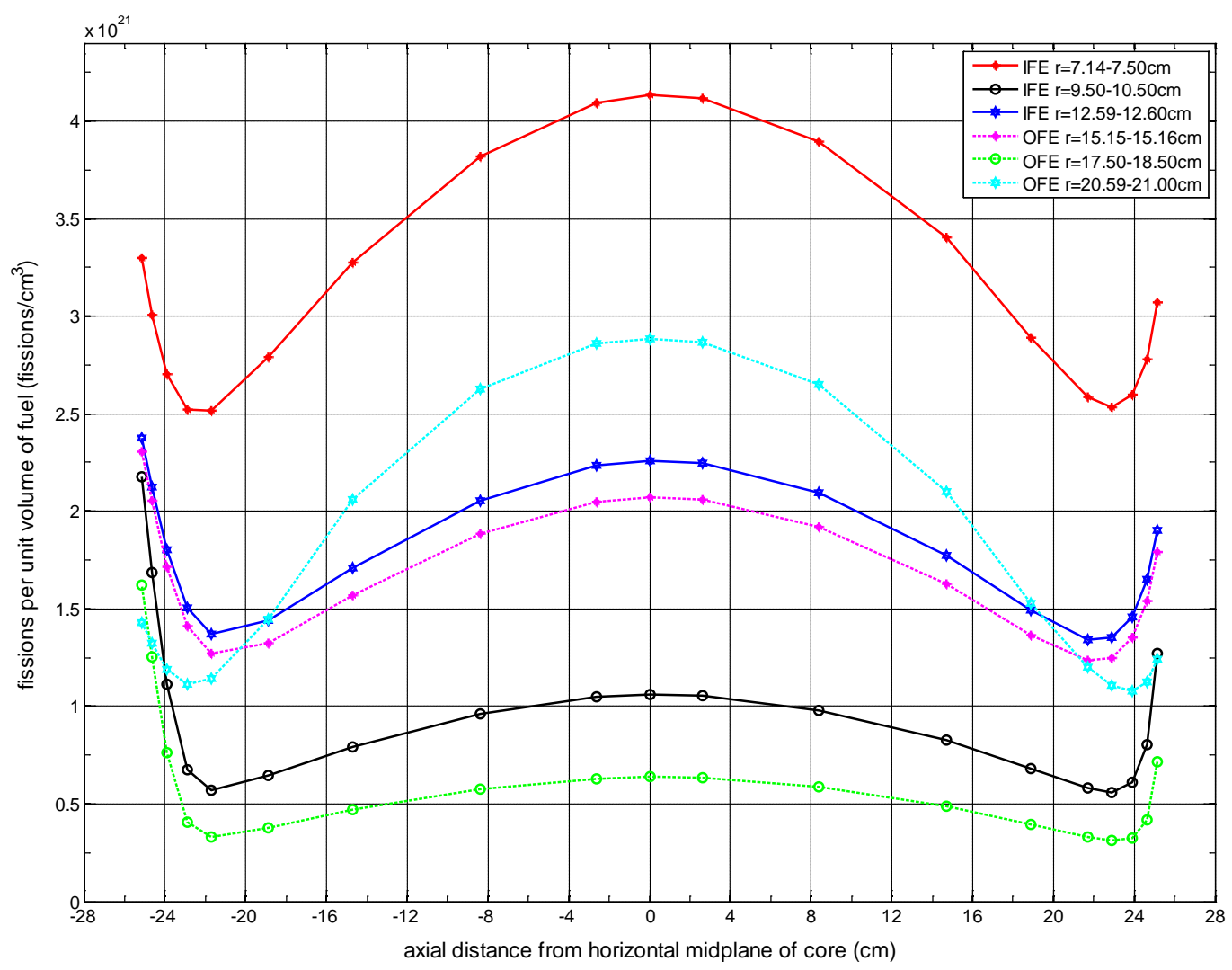

Fig. 9. Accumulated fission density (fissions $/ \mathrm{cm}^{3} \mathrm{UMo}$ ) axial profiles. 


\subsection{BURNUP DATA}

The fresh LEU core is loaded with about $25.3 \mathrm{~kg}$ of ${ }^{235} \mathrm{U}$ and following the 26 day irradiation cycle, about $22.0 \mathrm{~kg}$ of ${ }^{235} \mathrm{U}$ remains. Thus, approximately $12.7 \%$ of the initial ${ }^{235} \mathrm{U}$ is removed during the cycle, or equivalently, about $87.3 \%$ of the initial ${ }^{235} \mathrm{U}$ is present in the used fuel. The average burnup in terms of percent of ${ }^{235} \mathrm{U}$ atoms removed in one cycle for the IFE and OFE is 17.6 and $11.1 \%$, respectively. The maximum local burnup for all the defined fuel regions is $58.5 \%$, and this occurs at the innermost edge of the IFE at the core horizontal midplane. The minimum local burnup is $4.9 \%$ and this takes place in the OFE region bounded by radial dimensions 17.5 to $18.5 \mathrm{~cm}$ and axial dimensions +22.4 to $+23.4 \mathrm{~cm}$. The ${ }^{235} \mathrm{U}$ atom percent burnup is illustrated in Fig. 10 and listed in Table 9.

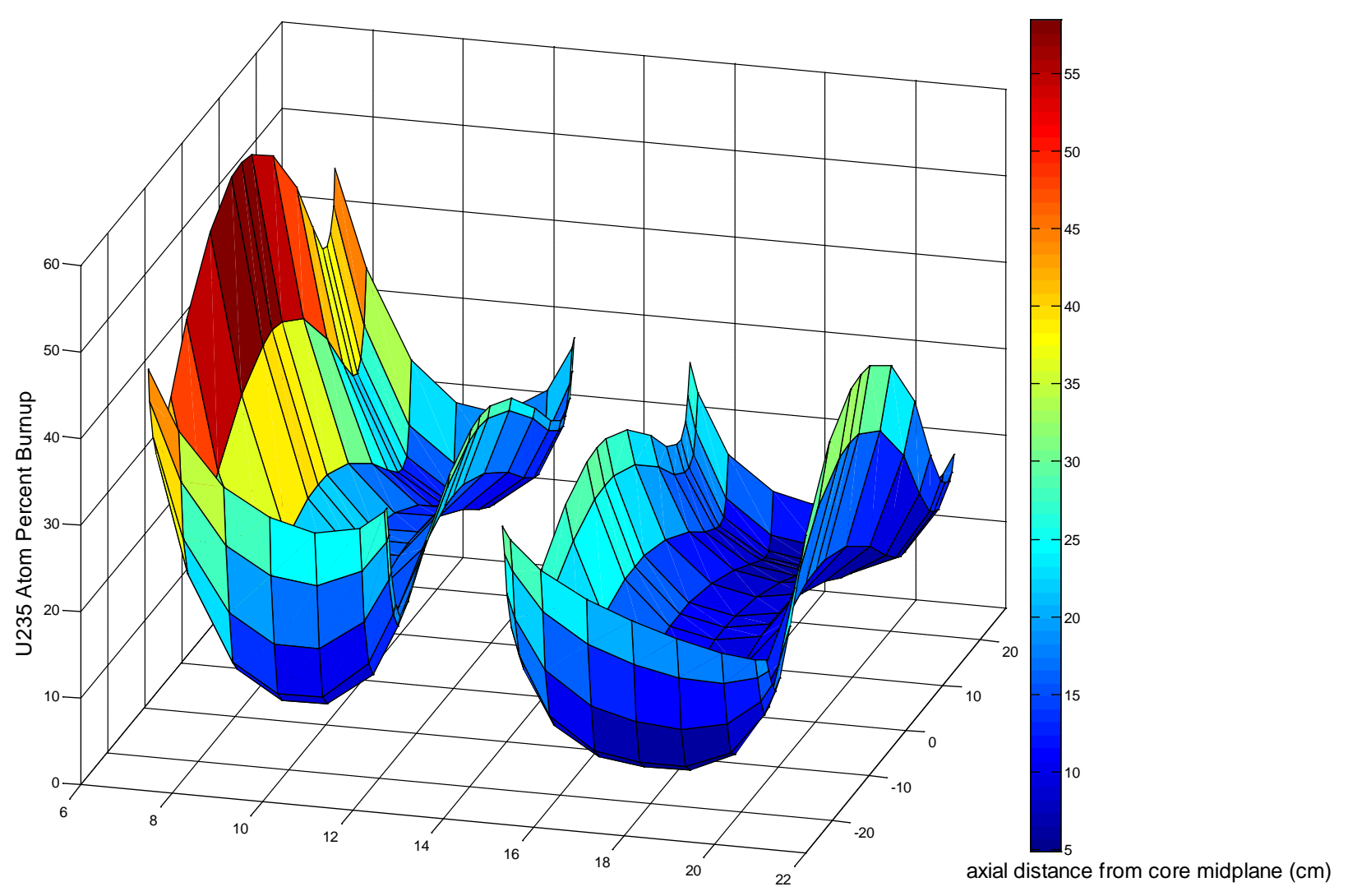

radial distance from core centerline $(\mathrm{cm})$

Fig. 10. Graphical representation of ${ }^{235} \mathrm{U}$ atom percent burnup. 
Table 9. ${ }^{235} \mathrm{U}$ atom percent burnup for HFIR LEU core

\begin{tabular}{|c|c|c|c|c|c|c|c|c|c|c|c|c|c|c|c|c|c|}
\hline \multirow{2}{*}{$\begin{array}{c}\text { Axial } \\
\text { region \# }\end{array}$} & \multicolumn{8}{|c|}{ IFE } & \multicolumn{9}{|c|}{ OFE } \\
\hline & $r=1$ & $r=2$ & $r=3$ & $r=4$ & $r=5$ & $r=6$ & $r=7$ & $r=8$ & $r=1$ & $r=2$ & $r=3$ & $r=4$ & $r=5$ & $r=6$ & $r=7$ & $r=8$ & $r=9$ \\
\hline 1 & 44.68 & 33.50 & 23.27 & 18.93 & 18.08 & 21.22 & 26.47 & 27.65 & 26.09 & 22.65 & 15.83 & 12.00 & 10.82 & 10.44 & 11.88 & 15.76 & 18.25 \\
\hline 2 & 40.50 & 27.09 & 16.07 & 12.11 & 11.84 & 16.02 & 22.60 & 4.00 & 22.45 & 18.55 & 11.04 & 7.30 & 6.40 & 6.38 & 8.36 & 13.29 & 16.49 \\
\hline 3 & 37.76 & 23.63 & 12.78 & 9.31 & 9.32 & 13.56 & 20.06 & 21.36 & 19.83 & 16.21 & 9.19 & 5.80 & 5.04 & 5.14 & 7.22 & 12.47 & 15.82 \\
\hline 4 & 36.81 & 22.44 & 11.84 & 8.61 & 8.72 & 12.71 & 18.62 & 19.81 & 18.34 & 15.09 & 8.73 & 5.60 & 4.87 & 5.03 & 7.19 & 12.67 & 16.15 \\
\hline 5 & 37.14 & 22.74 & 12.10 & 8.90 & 9.03 & 12.95 & 18.69 & 19.87 & 18.35 & 15.21 & 9.03 & 5.90 & 5.18 & 5.35 & 7.64 & 13.37 & 16.94 \\
\hline 6 & 41.15 & 25.66 & 13.84 & 10.23 & 10.32 & 14.36 & 20.15 & 21.30 & 19.63 & 16.48 & 10.15 & 6.84 & 6.05 & 6.35 & 9.39 & 16.85 & 21.39 \\
\hline 7 & 47.95 & 30.80 & 16.86 & 12.47 & 12.54 & & & & & 19.54 & 12.29 & 8.40 & 7.53 & 8.08 & 12.62 & 23.47 & 29.78 \\
\hline 8 & 54.86 & 36.32 & 20.18 & 14.88 & 14.97 & 20.47 & 27.94 & & 27.07 & 23.09 & 14.68 & 10.10 & 9.09 & 9.90 & 15.87 & & 37.26 \\
\hline 9 & & & & 16.11 & & & & & & & & & 9.87 & 10.79 & & & 40.30 \\
\hline 10 & 58.46 & & 22.07 & 16.26 & 16.32 & & & & & & 16.00 & & 9.96 & 10.89 & & 32.53 & 40.66 \\
\hline 11 & 58.07 & & 21.85 & 16.11 & 16.20 & & & & & & 15.87 & 10.95 & 9.87 & 10.79 & 17.36 & 32.22 & 40.30 \\
\hline 12 & & & 20.18 & 14.88 & 14.97 & 20.47 & & & 27.07 & & 14.68 & 10.10 & 9.09 & 9.90 & 15.87 & 29.62 & 37.26 \\
\hline 13 & & & & 12.47 & & & & & & & & 8.40 & 7.53 & 8.08 & 12.62 & 23.47 & 29.78 \\
\hline 14 & & 25.66 & 13.84 & 10.23 & 10.32 & & & & & 16.48 & 10.15 & 6.84 & 6.05 & 6.35 & 9.39 & 16.85 & 21.39 \\
\hline 15 & & & 12.10 & 8.90 & 9.03 & & & & & & 9.03 & 5.90 & 5.18 & 5.35 & 7.64 & 13.37 & 16.94 \\
\hline 16 & 36.84 & 23.22 & 13.50 & 10.31 & 10.46 & 14.78 & 20.77 & 21.90 & 20.52 & 17.31 & 10.71 & 7.20 & 6.30 & 6.35 & 8.31 & 13.14 & 16.05 \\
\hline 17 & 39.42 & 27.86 & 19.74 & 16.64 & 16.51 & 20.14 & 25.22 & 26.21 & 24.94 & 22.22 & 16.49 & 12.86 & 11.53 & 11.11 & 12.20 & 15.22 & 17.23 \\
\hline 18 & 43.81 & 34.86 & 27.94 & 24.84 & 24.17 & 26.42 & 30.05 & 30.80 & 29.89 & 27.98 & 23.73 & 20.38 & 18.58 & 17.52 & 17.33 & 18.33 & 19.26 \\
\hline 19 & 47.75 & 40.86 & 34.94 & 31.85 & 30.61 & 31.52 & 33.74 & 34.23 & 33.34 & 31.89 & 28.78 & 25.89 & 23.83 & 22.25 & 21.04 & 20.61 & 20.80 \\
\hline
\end{tabular}

${ }^{a} \mathrm{r}=\mathrm{n}$ denotes the radial region number; $\mathrm{n}$ varies from 1 to 8 for the IFE and from 1 to 9 for the OFE. 



\section{THERMAL HYDRAULICS PARAMETERS}

\subsection{HFIR STEADY-STATE HEAT TRANSFER CODE (HSSHTC) ANALYSIS}

The HSSHTC [6,7] is a steady-state channel code with 2D R-Z geometry nodes that correspond to the MCNP neutronic modeling nodes. The analysis solves integral mass, momentum, and energy equations on each axial coolant channel. The code searches the entire core for the worst hot streak and worst hot spot in that hot streak over the course of a fuel cycle, considering best-estimate modeling of the physical processes that affect the heat transfer and fluid flow. The code also models a multiplicative combination of process, manufacturing, modeling, and parameter uncertainties that are provided as inputs. The fuel internal conduction and energy generation is not explicitly modeled in the HSSHTC, only the local heat flux to reject the local power produced in the plates is considered. As a result, the HSSHTC only produces $2 \mathrm{D}$ distributions of plate surface temperatures.

The HSSHTC is tailored and focused on thermal analysis necessary to produce reactor limiting control settings (LCSs-equivalent to limiting safety system settings for NRC-regulated reactors) and safety limits (SLs) over the course of a fuel cycle. A typical HSSHTC calculation includes a first time step that corresponds to the beginning of cycle (BOC) and at least one last step that corresponds to the end of the fuel element irradiation under consideration, which could be the end of cycle (EOC) conditions. At each time step, the HSSHTC determines the average fuel temperatures and heat fluxes at the given power, then calculates the effects of manufacturing tolerances on the temperature and heat flux distributions, e.g., combined effects of wide and narrow coolant channels are considered. The HSSHTC always ends the last part of the core time step with a calculation of the power increase required to cause either hot spot incipient boiling or hot spot burnout (depending on the input choice) taken from the steady-state power and conditions at the end of the last step. Thus, the course of a fuel cycle is modeled by a series of quasistatic time steps that move the fuel through the cycle and allow the user to model the effects of changing power density distributions and oxide layer growth based on the calculated fuel conditions as the cycle evolves. If only the BOC conditions are desired, the code user inputs a timestep of 0.0 hours and the code outputs the BOC average, hot channel, and hot plate results.

The core thermal-hydraulic model includes numerous physical models that are connected and iteratively solved together with the mass, momentum, and energy balance to consider the effects on local coolant channel width caused by: oxide layer growth, plate thermal expansion, plate radiation swelling, plate deflections due to axial thermal expansion differences between the hot plate center and cool plate edges, plate deflection due to axial temperature gradients between an adjacent hot plate (overloaded with fuel) and cold plate (underloaded with fuel), and azimuthal pressure gradients caused by velocity difference between adjacent wide and narrow coolant channels. These models were not changed for this study (they include characteristics of HEU dispersion fuel) and were applied to the extent possible for the LEU fuel calculations. In some cases the models are conservative, e.g., because the HEU plate deflections and effects on coolant channels are expected to be greater than the corresponding LEU deflections. In some cases the models are nonconservative, e.g., the current model has the radiation swelling calculation turned off because this has been shown to not be a problem for HFIR HEU dispersion fuel. However, radiation swelling could be an important parameter to model for any final LEU calculations performed with the HSSHTC.

The HSSHTC includes numerous uncertainty factors to consider process uncertainties, manufacturing uncertainties, uncertainties in correlations, and uncertainties in input parameters. To produce nominal temperature and heat flux information for the fuel development experiments, the manufacturing uncertainties, model uncertainties, correlation uncertainties, and most input parameter modeling uncertainties were set to "1.0." Key input adjustments and uncertainties that were retained 
include a factor of 0.975 to model the assumption that $2.5 \%$ of the energy produced by the reactor could be deposited outside the fuel meat, i.e., in the coolant, target, reflector, and surrounding structures. The code does not track any of this lost energy —it only follows the power deposited in the fuel meat.

The calculations were performed considering a factor of 1.09 on the normalized power density distribution to consider the local effects that occur due to flux tilts when strong-absorbing experiments are placed near the core.

To get EOC results for a nominal 100 MW LEU cycle to support this report, the code input was used to cause burnout with an artificial uncertainty factor in an unfueled node located just below the core. This was done using a factor, U25, which normally models fabrication and assembly uncertainties that could cause an extension of a plate past the nominal end of the active core. For these calculations all of the U25s were "1.0" except one, which was turned up to get convergence of the hot spot heat flux to burnout for a reactor power of 100MW. This allowed the code to run to completion properly and include consideration of important physical effects - such as the asymmetric heat flux over the thickness of the HFIR plates due to the location of the fuel meat closer to the concave side of the involute - without causing any significant perturbation on the resultant temperature and heat flux distributions.

To avoid code problems with the models that mimic the effects of adjacent narrow and wide channels in combination with hot and cold plates, the wide and narrow channels were modeled as a nominal channel (0.050 in. wide) plus or minus 0.001 inches deviation. The hot and cold channel uncertainty factors, plus axial fuel distribution uncertainty factors, were all set to 1.0.

\subsection{HFIR POWER DENSITY PROFILES}

The local power density profiles in units of watts $/ \mathrm{cm}^{3}$ are shown in Figs. 11-13. These plots were produced based on the MCNP normalized relative fission density profiles, which tally the total number of fissions in a given r-z cell (MCNP volume) and use the appropriate average U10-Mo fuel thickness and cell height to produce local power density profiles consistent with a reactor power of $100 \mathrm{MW}$. This power density profile is used without any adjustment for the thermal power added to the reactor by the primary coolant pumps.

The 3D plots shown in Fig. 11 show the inner edge of the inner element to be a region of high local power density throughout the cycle. This is likely due to the effects of the peak thermal and fast neutron flux in the target region. Also apparent on these plots are peaks at the outer edge of the outer element, which are due to the neutrons coming from the beryllium reflector through the cylindrical window created by the gap between the control cylinder and safety plates. As seen in Figures 11 and 13, the axial peak at the inner edge of the inner element and the outer edge of the outer element broadens and lowers as the cycle progresses and the control cylinder-safety plate window opens due to fuel burnup and fission product poisoning.

A 2D radial slice through the inner and outer elements at the top of the active fuel (TOAF), core midplane, and bottom of active fuel (BOAF) is shown in Fig. 12. The plots of Fig. 12 include BOC and EOC conditions. The magnitudes of the major power density peaks at the inner edge of the inner element and outer edge of the outer element are provided on this figure, as well as the minor peaks at the fuel plate edges that are interior to the core and adjacent to the fuel element water gap.

A 2D axial slice through the inner and outer elements at the inner edge of the active fuel, near the center of the involute curve, and at the outer edge of the active fuel is shown in Fig. 13. The plots of Fig. 13 include beginning of cycle (BOC) and end of cycle (EOC) conditions. The magnitudes of the major power density peaks due to the axial water reflector at the upper and lower ends are shown on this figure, 
as well as the major peak at the midplane of the core. The effects of the control cylinder-safety plate window are seen in this figure due to the high and narrow power density peak at core midplane at BOC, which broadens and lowers as the cycle progresses to EOC conditions shown in Fig. 13.

Input to the HSSHTC is in the form of normalized local to average power density profiles, which correspond directly to the normalized fission density profiles produced by MCNP. Figure 14 shows 3D EXCEL plots for the inner and outer elements at BOC conditions, which correspond to the power density plots at Day 0 shown in Fig. 11.
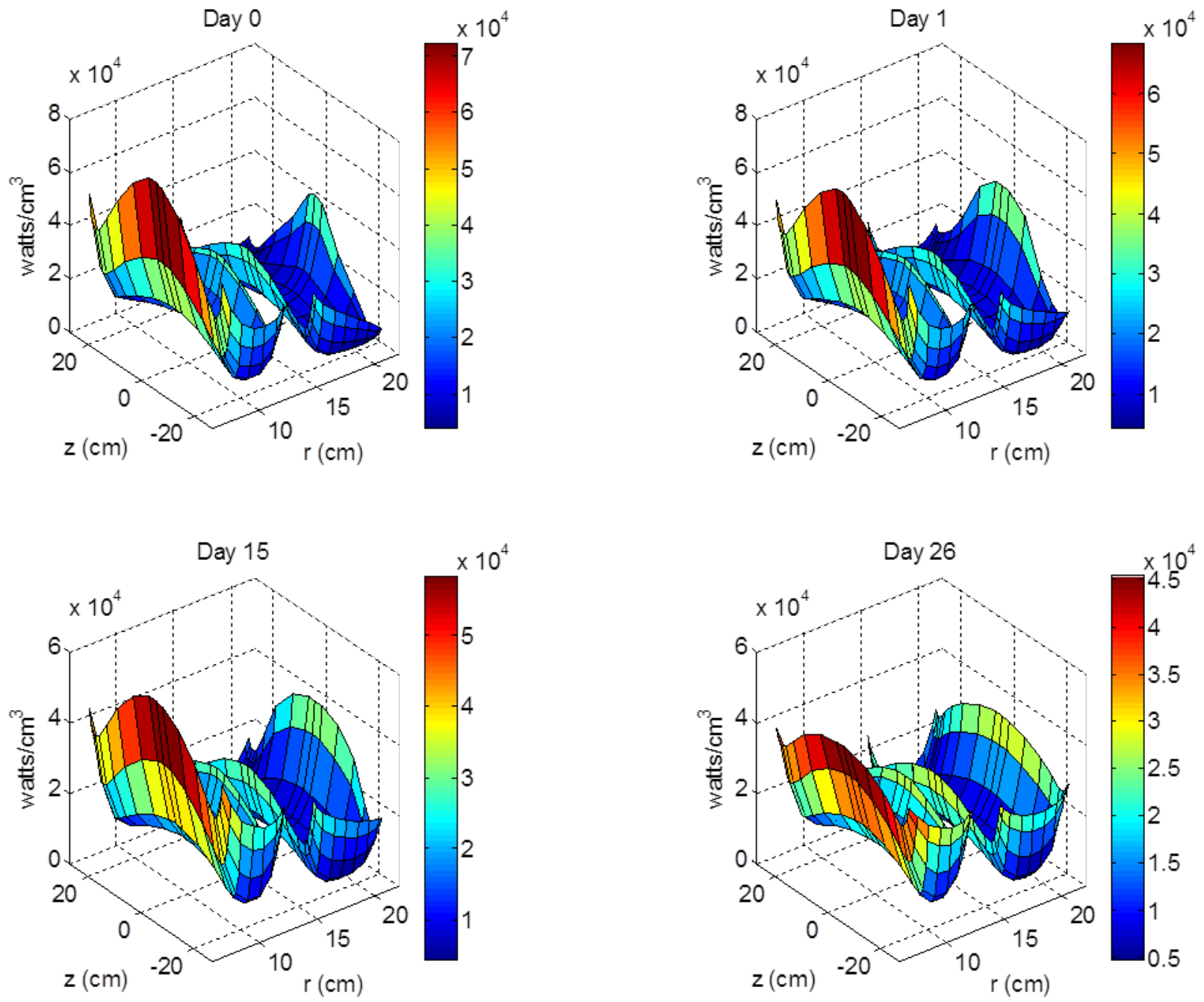

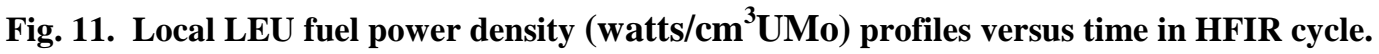




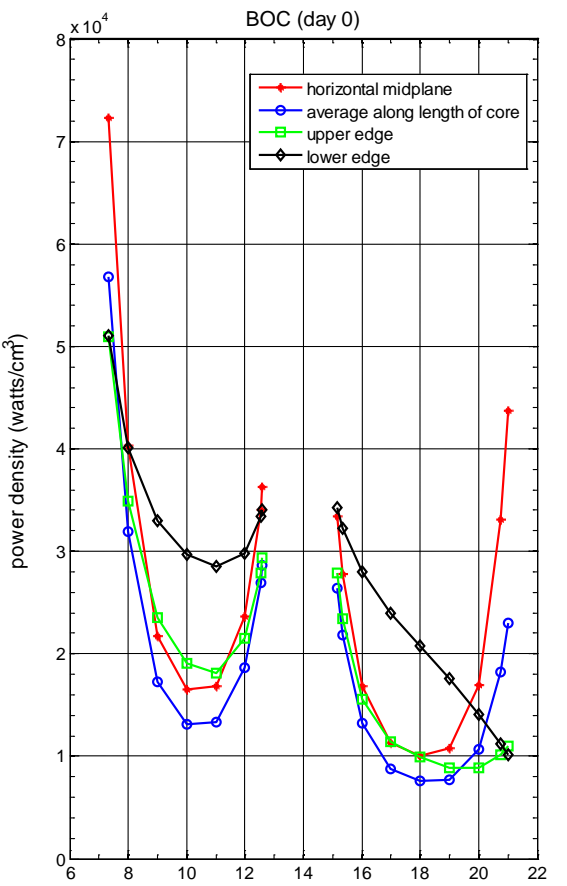

radial distance from longitudinal centerline of core $(\mathrm{cm})$

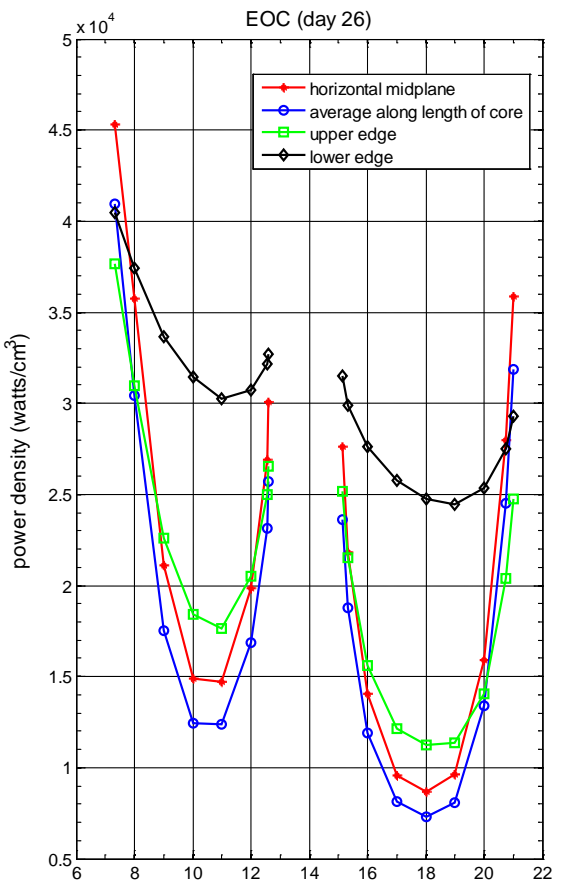

radial distance from longitudinal centerline of core $(\mathrm{cm})$

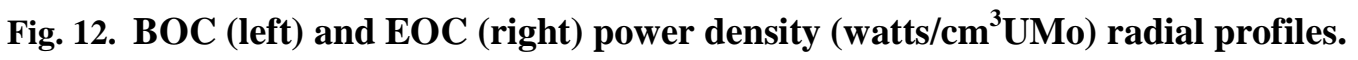
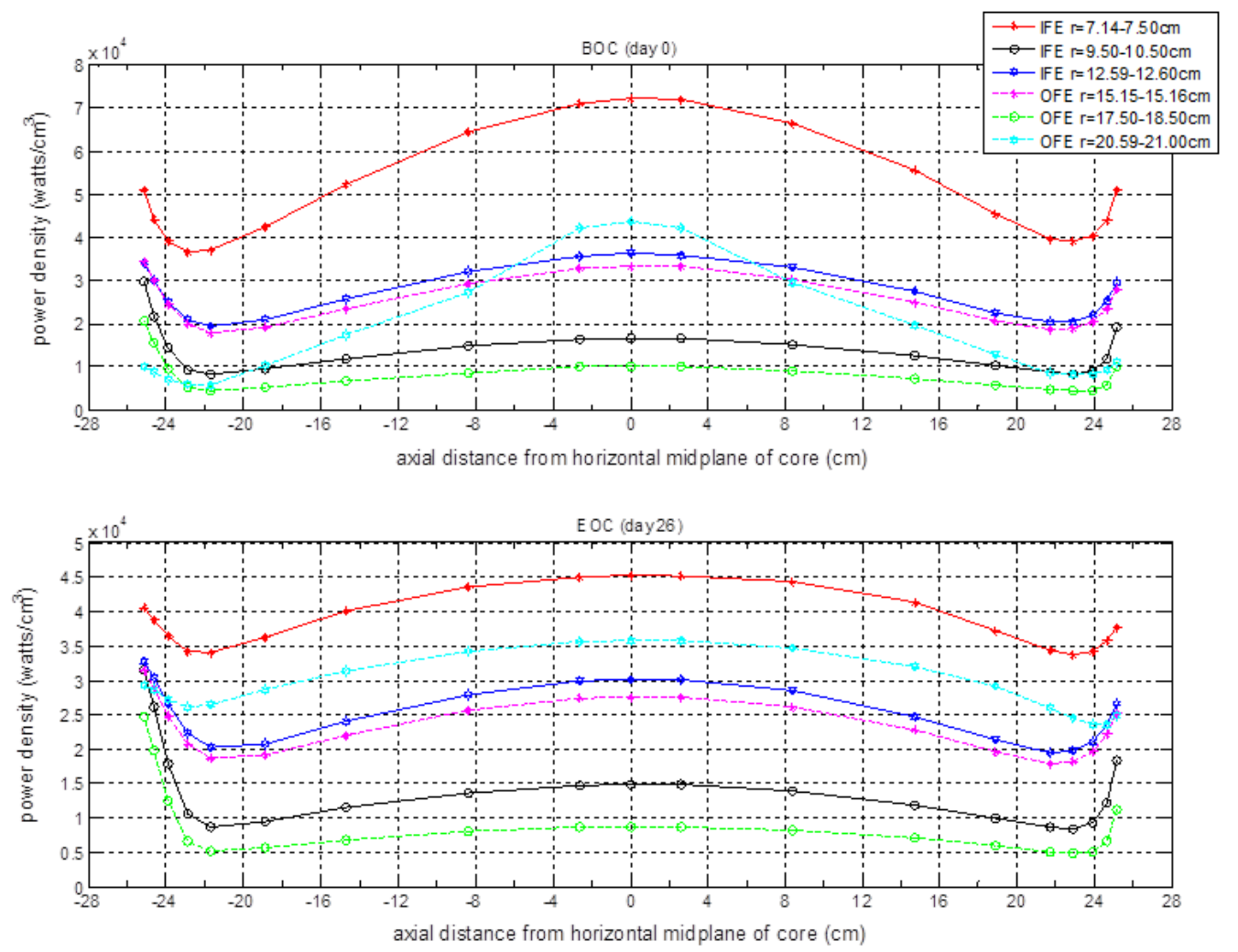

Fig. 13. BOC (top) and EOC (bottom) power density (watts/ $\mathrm{cm}^{3} \mathrm{UMo}$ ) axial profiles. 

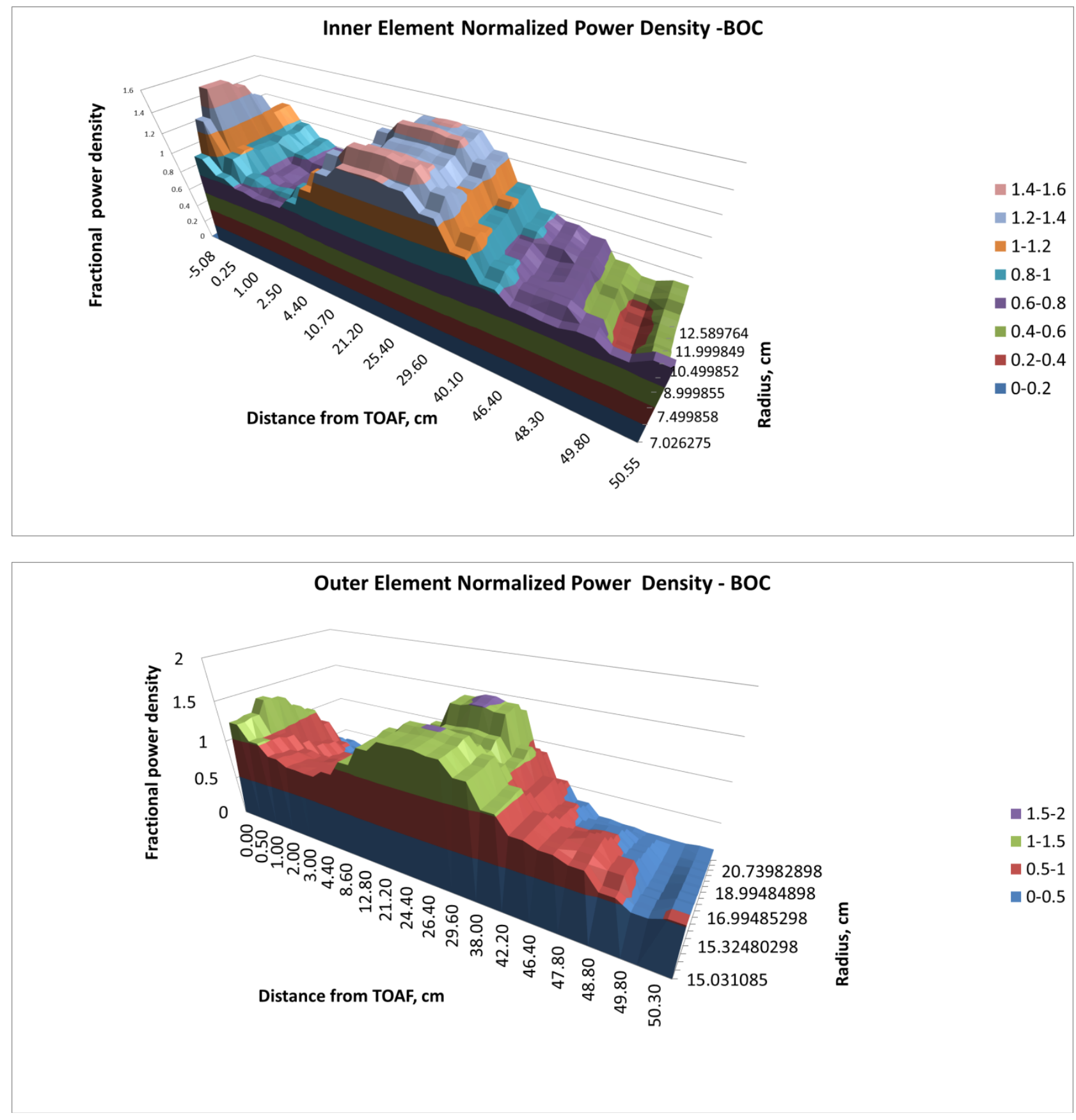

Fig. 14. Normalized local-to-average power density for BOC inner and outer elements.

\subsection{HFIR FUEL PLATE SURFACE TEMPERATURE PROFILES}

The HSSHTC calculates channel effects and does not include an explicit model of the fuel plate peak internal temperature. However, the code does consider plate internal effects and the influence on surface heat flux through a hardwired polynomial that models the fuel meat location across the thickness 
of the plate and the fuel meat thickness as a function of distance along the width of the involute. The hot and cold sides of the plate are the concave and convex sides of the involute, respectively. In order to only include the hot surface effects on temperature and heat flux which apply to the concave side of the involute, the HSSHTC was run in a mode to converge to $100 \mathrm{MW}$ with all input uncertainties set to 1.0, except for the power density uncertainty of 1.09 as was discussed in Section 3.1. The temperatures presented in this section are fuel plate surface temperatures, which represent the surface temperature of the cladding at BOC conditions and of the oxide layer for all subsequent timesteps.

Axial profiles of the fuel plate surface temperature for the inner and outer element at the BOC are shown in Fig. 15. The inner edge temperature of both elements is higher for most of the fuel plate length, except for the outer element, with outer edge temperatures being higher near the core midplane. This is consistent with the power density profile.

Axial profiles of the temperature for the inner and outer element at the EOC are shown in Fig. 16. The inner edge temperature of the inner elements is higher for most of the fuel plate length and the outer edge temperature of the outer element is higher over the fuel length. This is also consistent with the power density profile.

Three-dimensional plots of the temperature distribution for the inner element at BOC and EOC are shown in Fig. 17. A slight lowering of the temperature profile along the inner edge is evident from BOC to EOC. Similar three-dimensional temperature distributions are shown for the outer element in Fig. 18. The effect of the control plate window on plate surface temperature is shown in this figure as the temperature peak along the outer edge of the outer element lowers and broadens as the control plates withdraw. 

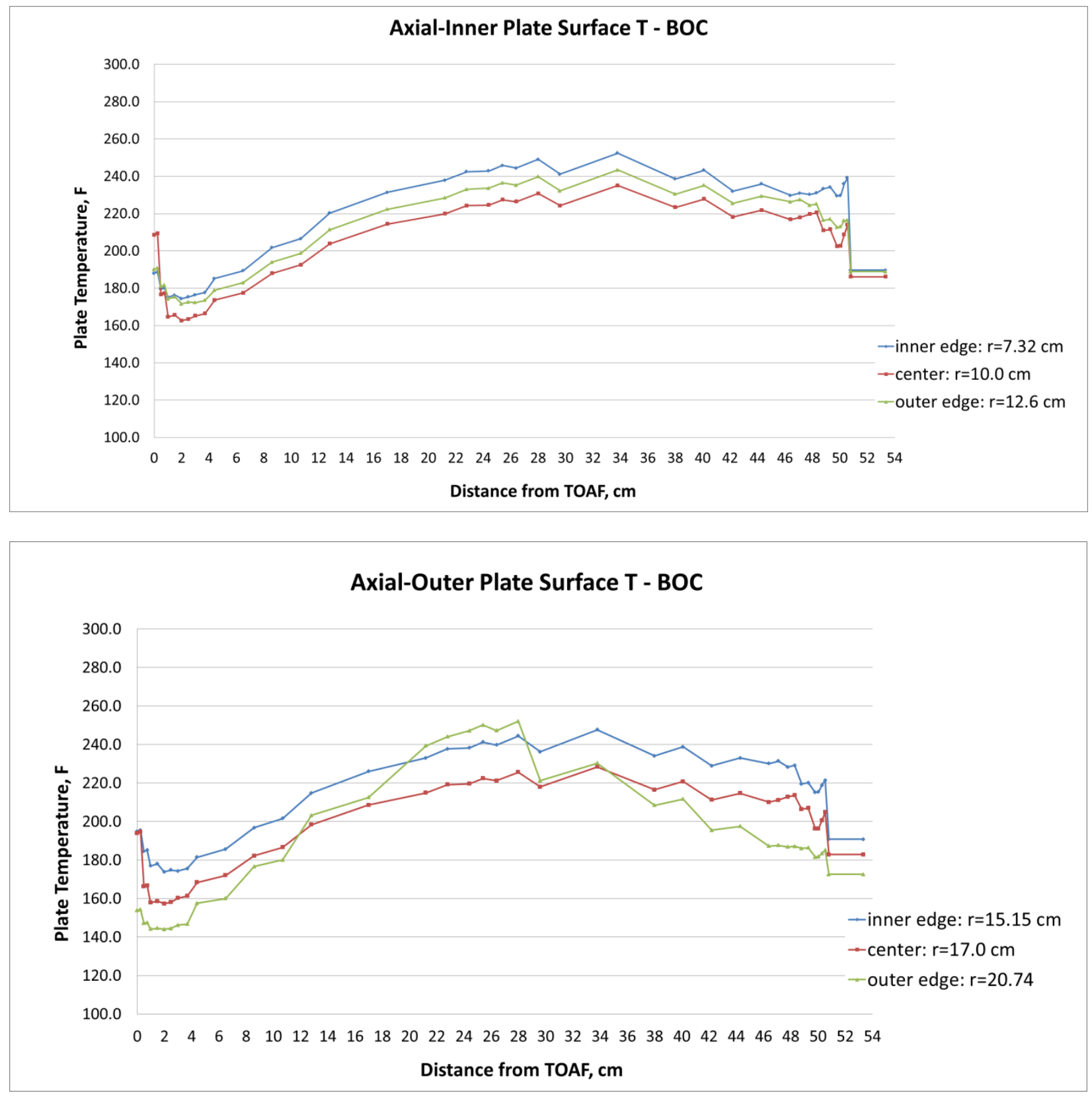

Fig. 15. Axial profile of plate surface temperature at BOC for inner and outer elements. 

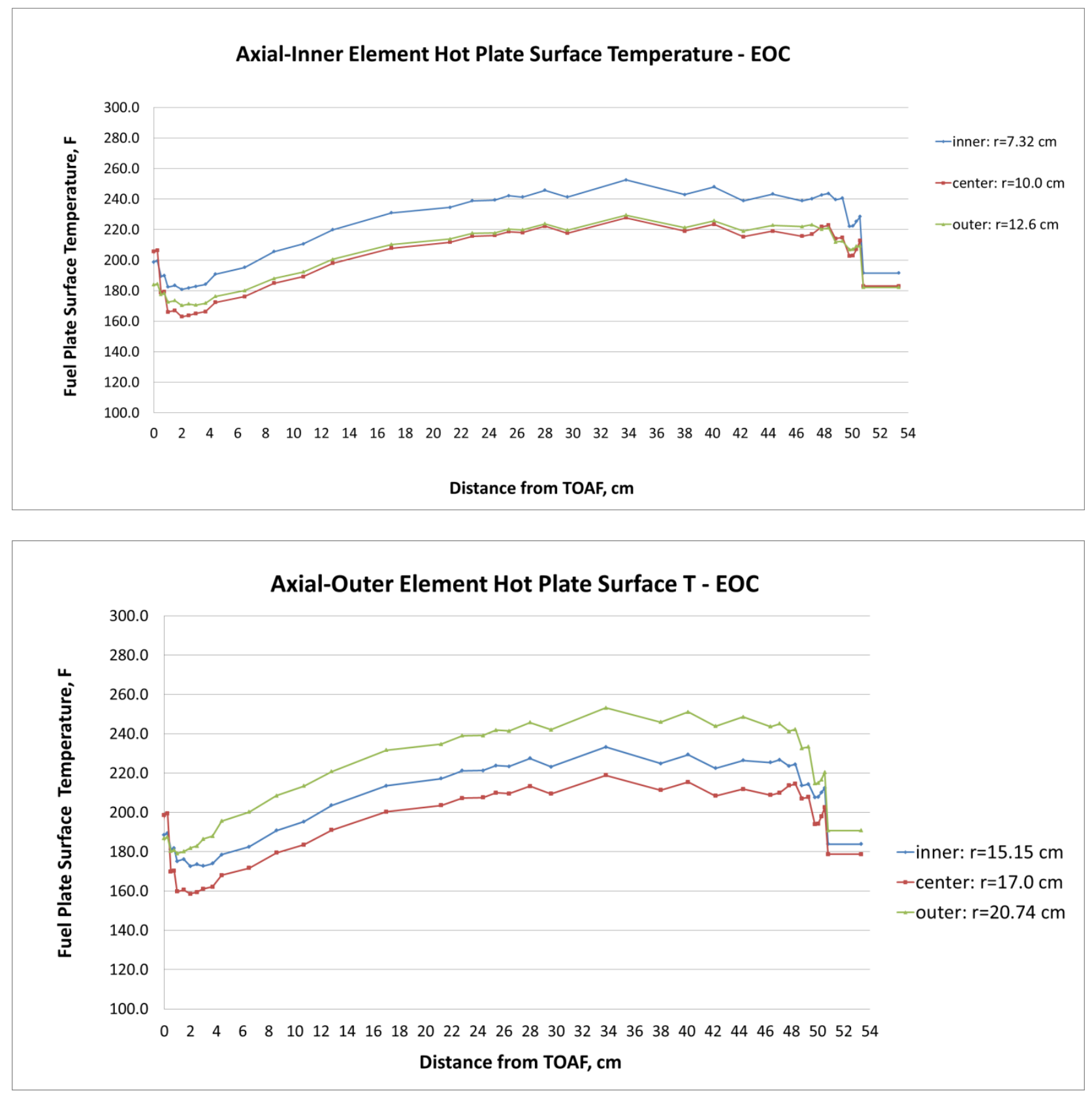

Fig. 16. Axial profile of plate surface temperature for EOC, inner and outer elements. 
Inner Element Hot Plate Surface Temperature-BOC

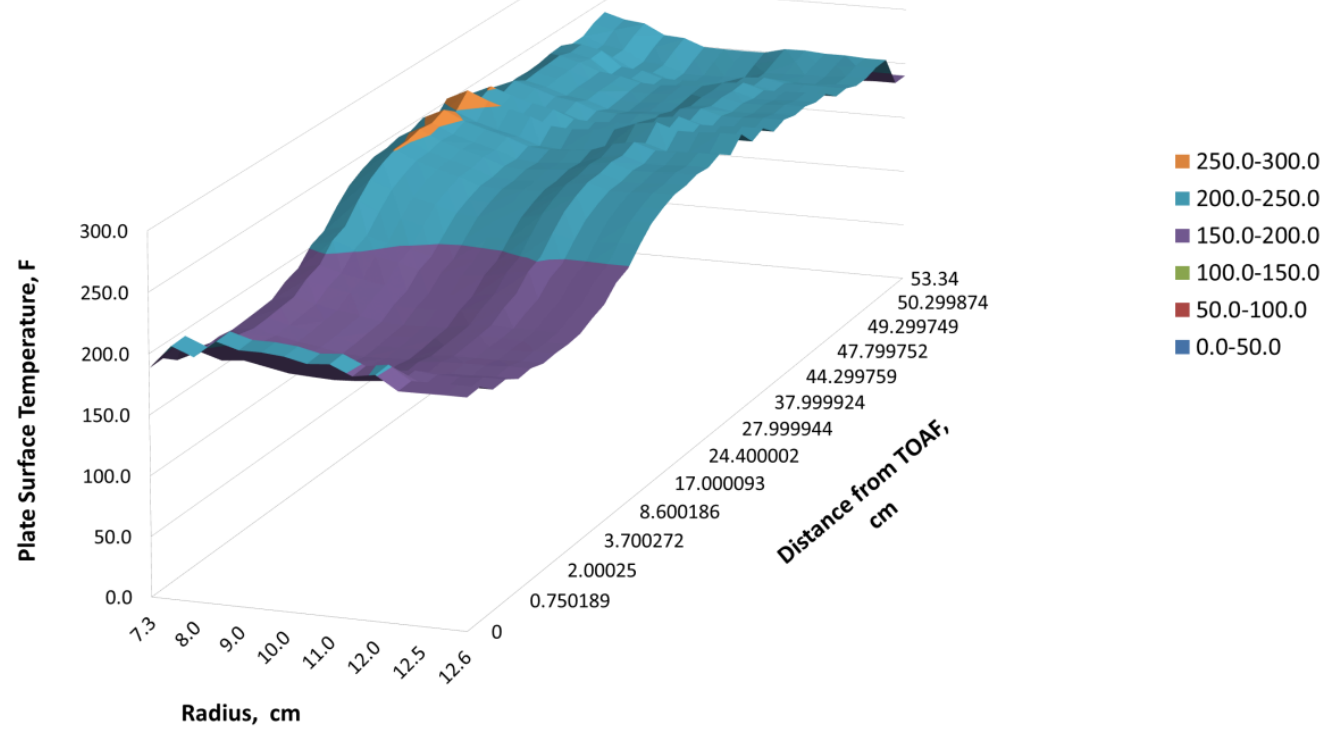

Inner Element Hot Plate Surface Temperature-EOC

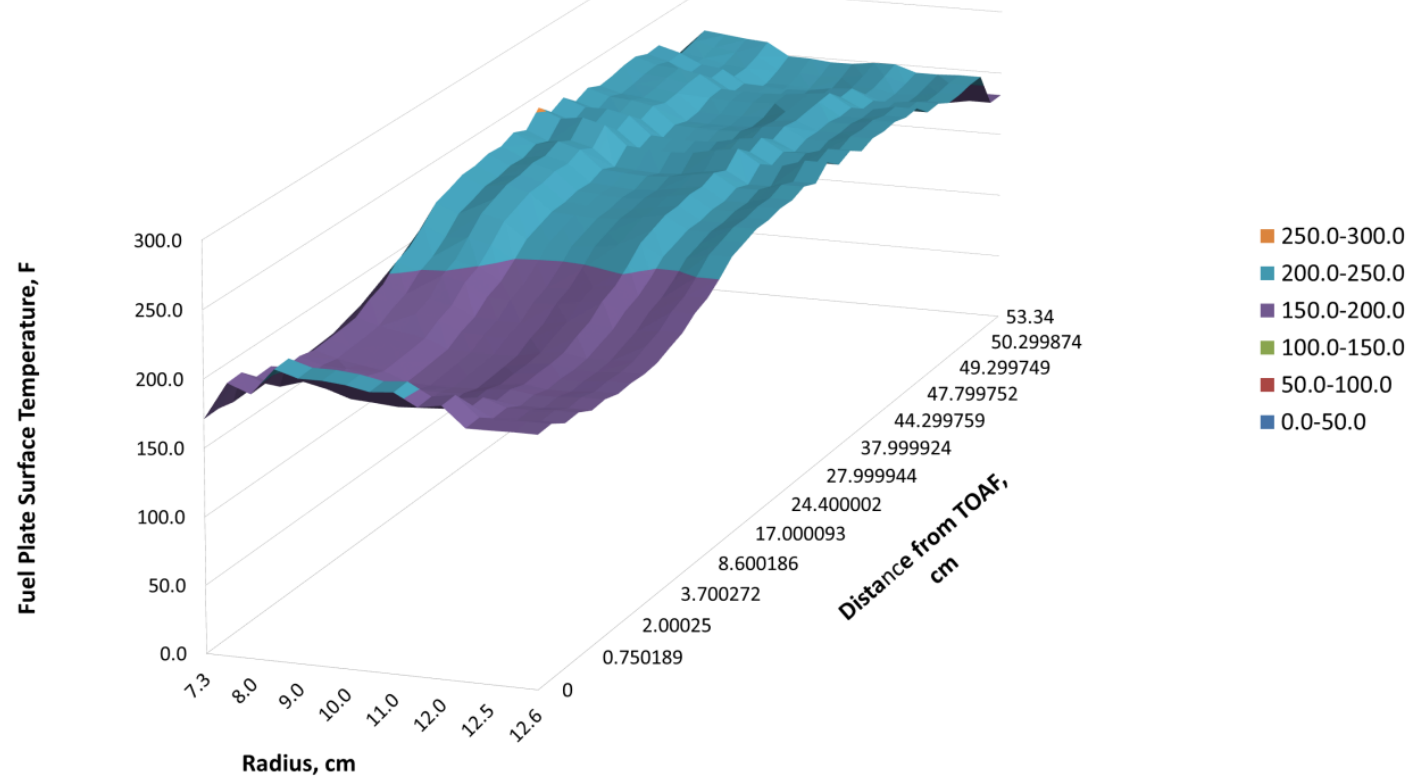

Fig. 17. Three-D profiles of plate surface temperature for inner element at BOC and EOC. 


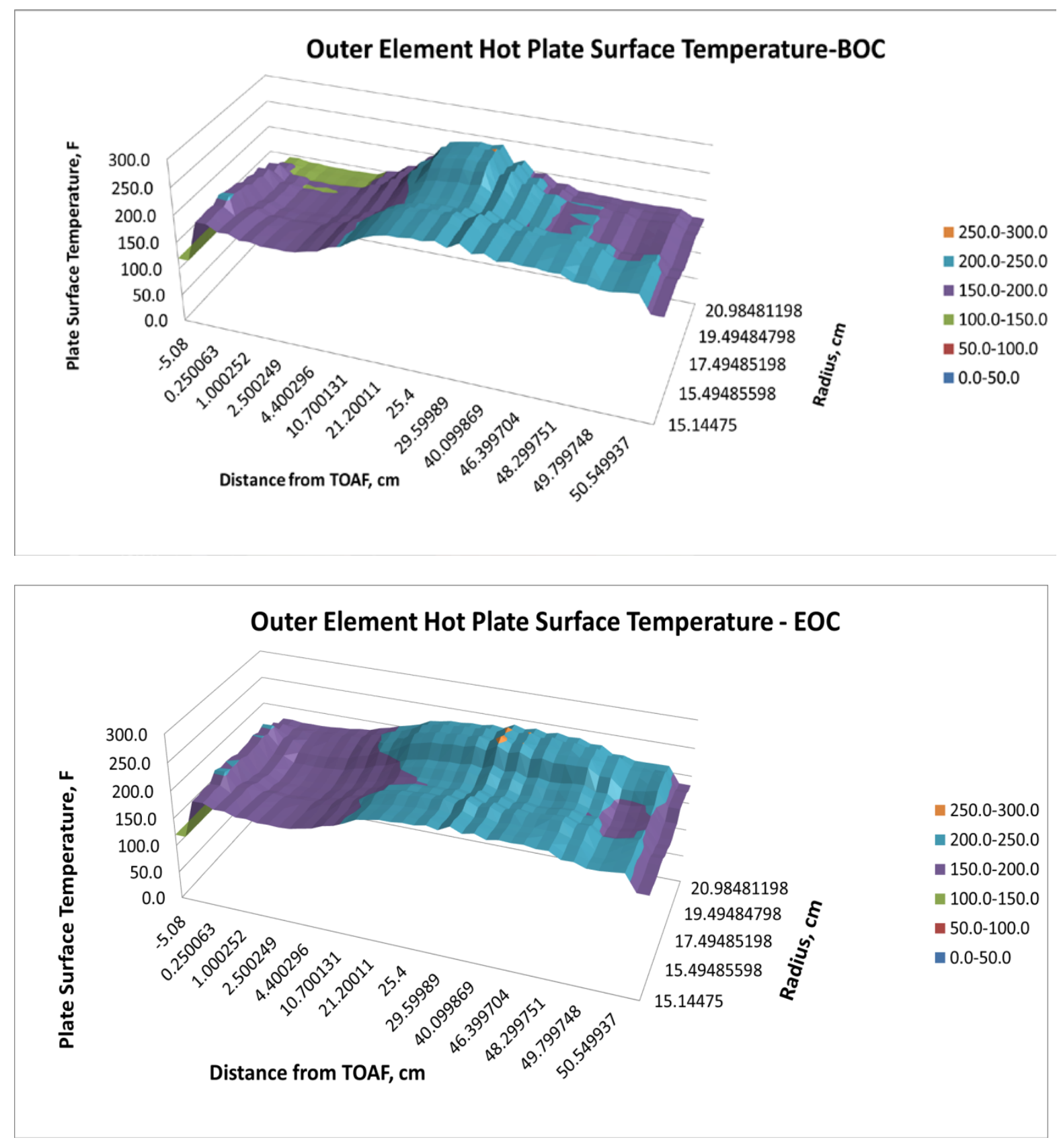

Fig. 18. Three-D profiles of plate surface temperature for outer element at BOC and EOC. 


\subsection{HFIR FUEL PLATE SURFACE HEAT FLUX PROFILES}

The heat flux distributions for the inner element at BOC, at peak xenon conditions (day 1 of the cycle), and at EOC are shown in Fig. 19. At the BOC, the heat flux for approximately the middle half of the plates is in the $400-500 \mathrm{~W} / \mathrm{cm}^{2}$ range, with a slight peak along the inner edge. The core-wide peak heat flux at BOC is $530.5 \mathrm{~W} / \mathrm{cm}^{2}$, at the inner edge of the inner element at the core centerline nodes. At day 1 , the inner element peak heat fluxes are along the inner edge and have dropped slightly to the 350$450 \mathrm{~W} / \mathrm{cm}^{2}$ range. By EOC, the inner element heat fluxes have dropped to the $250-350 \mathrm{~W} / \mathrm{cm}^{2}$ range and the axial distribution is broader, as shown by the lower plot in Fig. 21. The inner element peak has moved to the outer edge of the plates by the EOC, consistent with the power density shift.

The heat flux distributions for the outer element at BOC, at peak xenon conditions, and at EOC are shown in Fig. 20. The peak heat fluxes for the outer element are consistently higher along the outer edge and the peak of the axial distribution is more pronounced than that of the inner element. This behavior is attributable to the effect of the control cylinder-safety plate window and the enhanced fission rate caused by neutrons entering the core from the beryllium reflector. The core-wide peak heat flux for the outer element is $590.2 \mathrm{~W} / \mathrm{cm} 2$, which occurs on the outer edge near the core centerline nodes on day 1of the cycle.

The effect of the control element window on the heat flux for the outer element is quite dramatic, as shown in Fig. 21 by the three-dimensional heat flux distribution at day 1 of the cycle. 

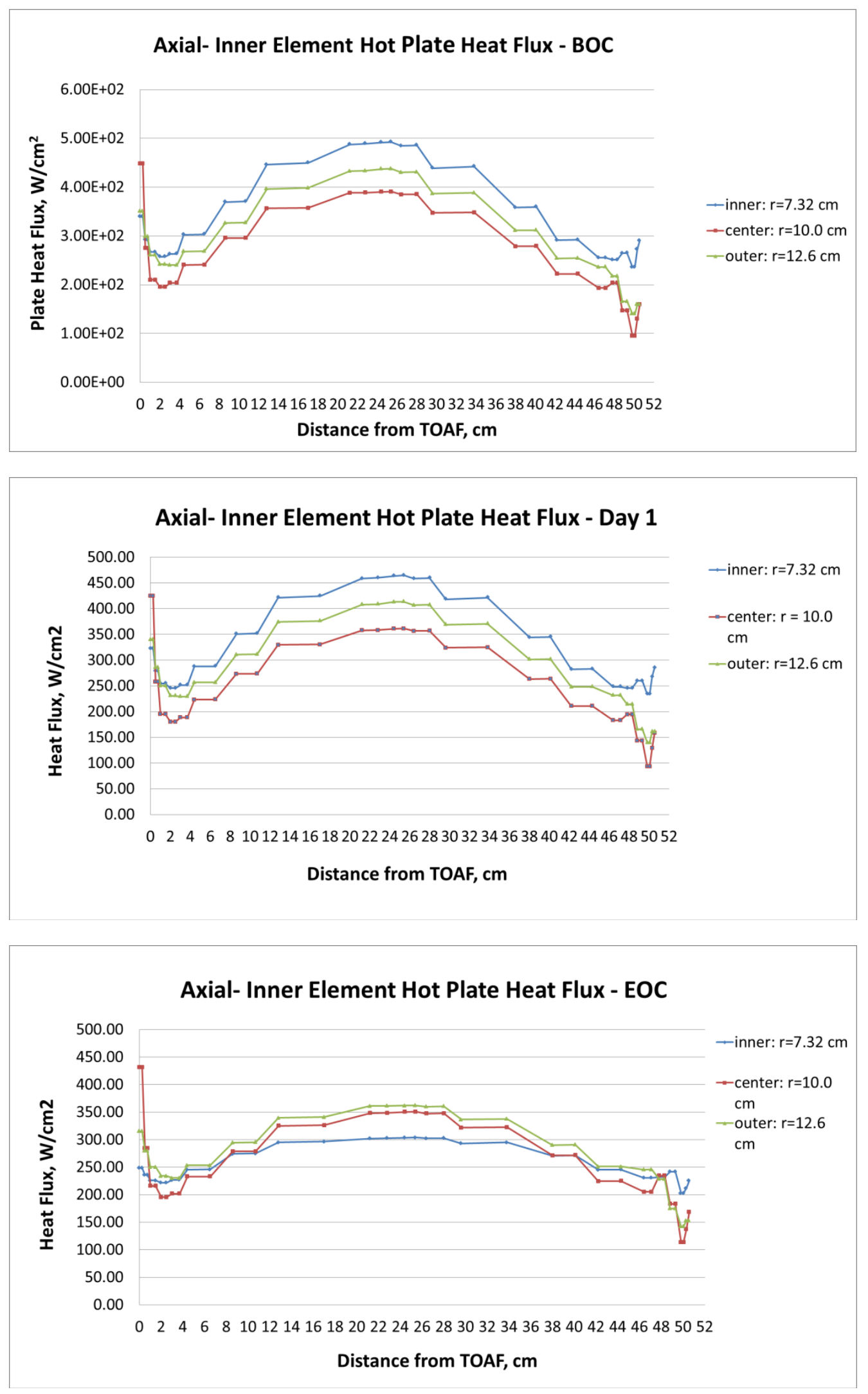

Fig. 19. Heat flux distributions for inner element at BOC, peak xenon (day 1), and EOC. 

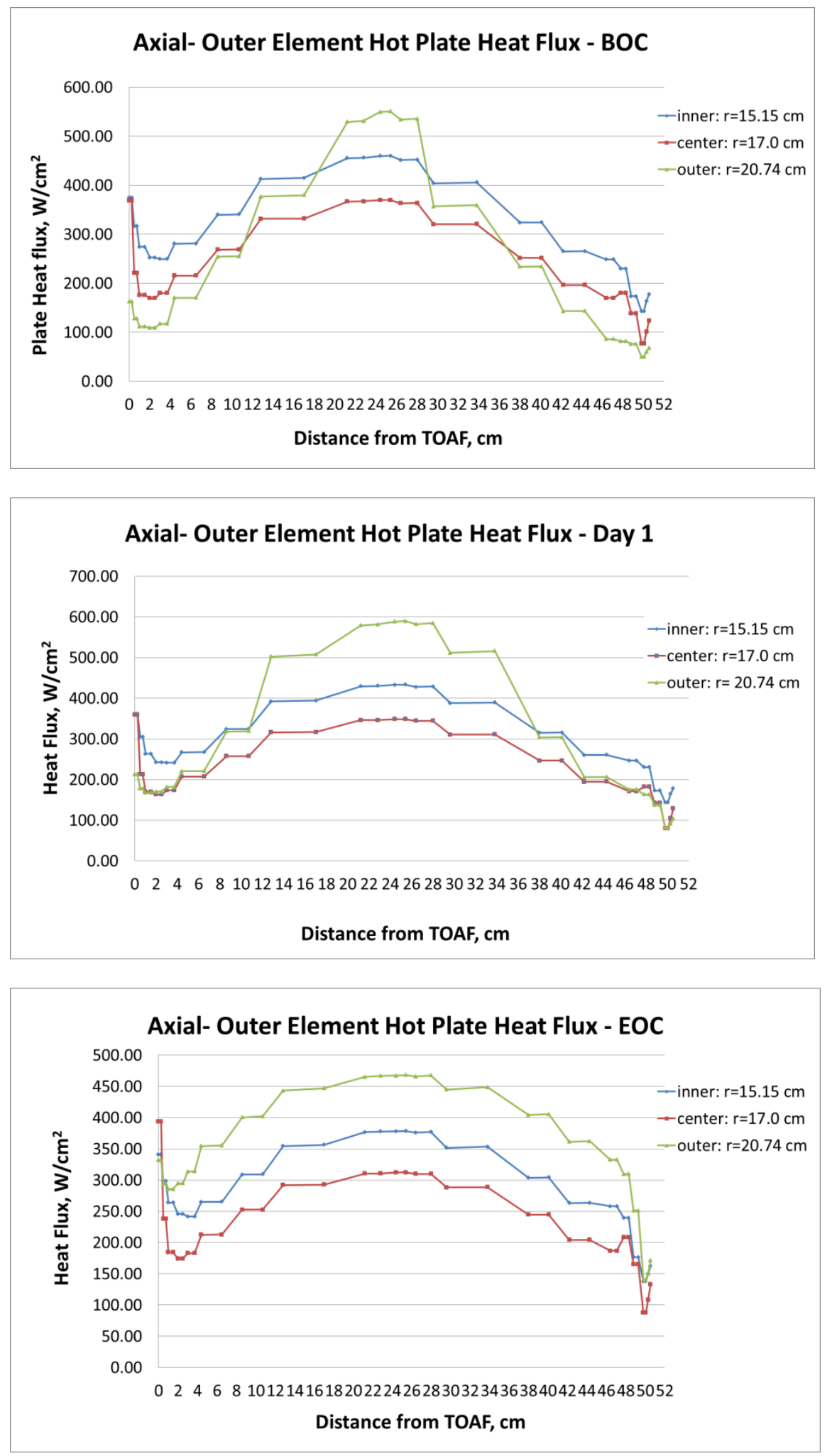

Fig. 20. Heat flux profiles for outer element at BOC, peak xenon (day 1), and EOC. 


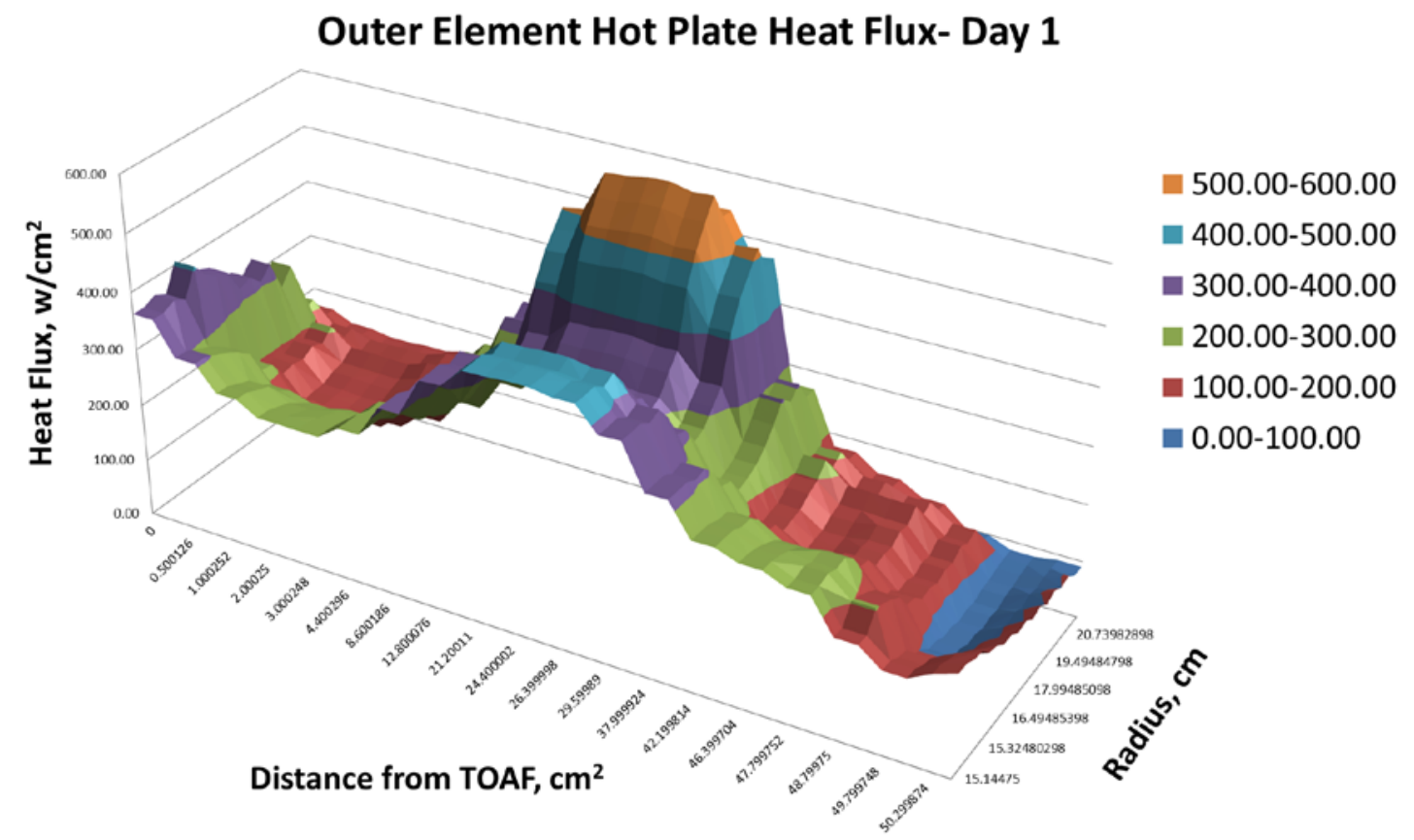

Fig. 21. Three -D plot of outer element heat flux distribution at peak xenon (day 1).

\subsection{COMPARISON OF HSSHTC RESULTS TO HFIR COMSOL MODEL RESULTS}

The ORNL models of the HFIR fuel using the COMSOL multiphysics code [8,9] were run using a single plate/single channel model of the HFIR fuel elements at nominal conditions as an independent review of the HSSHTC nominal temperature and heat flux calculations. This was done as a rough comparison to ensure the HSSHTC results provided in Sections 3.3 and 3.4 were reasonable, given the assumptions involved in modeling the LEU fuel by adjusting the input parameters to the HSSHTC, which is an HEU dispersion fuel-based model.

There are many differences in modeling between the HSSHTC, which is primarily a channel code, and COMSOL, which solves the coupled steady-state conduction problem in the fuel and the fluid equations in the channel. For example, the COMSOL model provides fuel plate internal temperatures which capture the peak U-Mo meat temperature and explicitly represents the involute plate hot side and cold side heat flux differences. Comparable peak fuel meat temperature information must be estimated by post-processing the HSSHTC surface temperature, heat flux, and oxide thickness results with an appropriate model of the LEU fuel plate interior. In this regard, COMSOL produces results that are a better estimate of the difference between the peak U-Mo meat temperature with respect to plate surface conditions than with the HSSHTC.

The COMSOL model of the plate accurately captures the radial variation in the fuel meat thickness for the U-Mo region and the asymmetric placement of the meat in the plate, and distributes the power density along the involute according to the MCNP fission density distribution. The HSSHTC 
includes a heat flux peaking factor that is a function of distance along the involute to capture the variation in heat flux due to varying fuel thickness.

Another example of differences in the models is in consideration of fuel plate oxidation and fuel plate thermal expansion. The HSSHTC incorporates the Griess model for fuel plate oxidation to couple the growth of the oxide layer as a function of fuel plate surface temperature and time through the cycle to the thermal hydraulics by adjusting the local channel thickness. The COMSOL model does not include the EOC oxide layer or change the fuel channel thickness with temperature--only the EOC power density changes are included to characterize the change in fuel temperature and heat flux over a cycle. In modeling the effects of the oxide layer on fuel temperatures and heat flux, the HSSHTC results are considered more accurate.

COMSOL results for inner and outer fuel plate surface temperature distributions at the BOC and EOC are shown in Fig. 22, and for the fuel meat centerline (peak) temperature in Fig. 23. COMSOL results for the inner and outer fuel plate heat flux distributions at the BOC and EOC are shown in Fig. 24.

Table 10 provides a comparison of HSSHTC and COMSOL results for the peak surface temperatures, heat fluxes, and fuel meat temperatures of the inner and outer elements at BOC and EOC conditions. For the peak U-Mo meat temperature comparison in Table 10, the HSSHTC local conditions of hot side surface temperature, hot side heat flux, power density, oxide thickness, and fuel region thickness were used as input to a one-dimensional conduction model of the fuel plate with heat generation in the fuel meat region to determine the peak fuel meat temperature. The HSSHTC input and postprocessed fuel meat peak temperature estimates are provided in Table 11 for the inner and outer elements at the BOC, day 1 of the cycle, and at the EOC.

There is good agreement between the HSSHTC calculations and the independent COMSOL analysis, considering the numerous differences between the modeling approaches.

For the irradiation experiment nominal calculations, the HSSHTC results are considered to be a good estimate for the experimental temperature and heat flux conditions at the plate surface. For the peak U-Mo meat temperatures, the peak temperature produced by post-processing the HSSHTC results may be slightly under-predicted. Before a final experimental testing specification is complete, confirmatory calculations of the nominal conditions should be issued including a more complete comparison between COMSOL and HSSHTC results. 


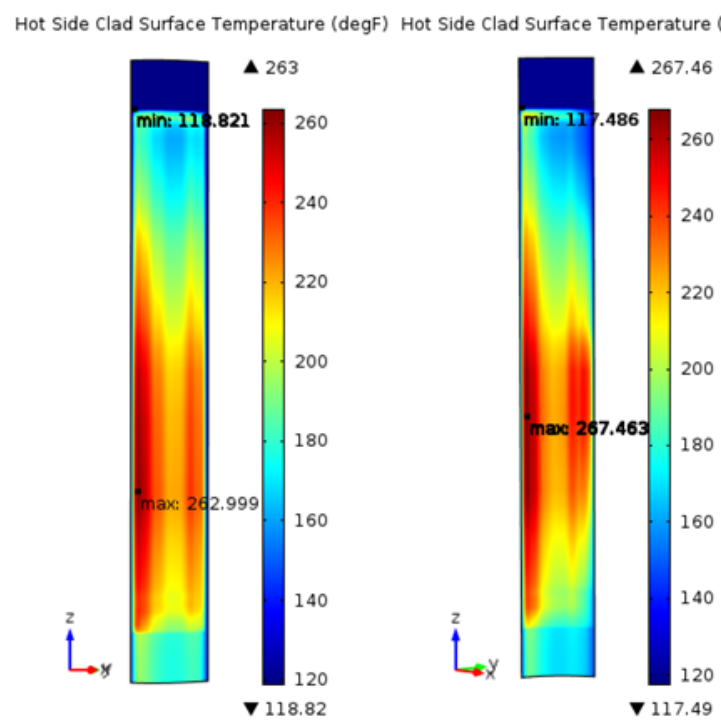

(a) Inner and outer plate at BOC
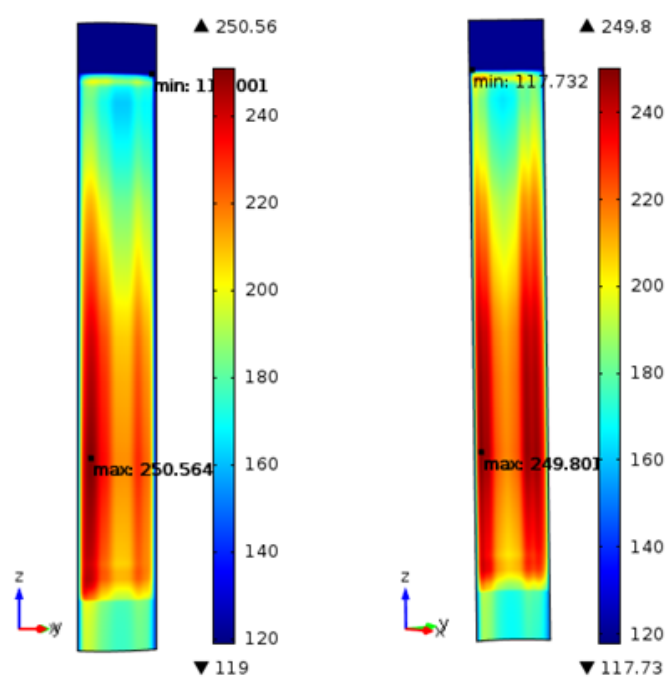

(b) Inner and outer plate at EOC

Fig. 22. COMSOL profiles of plate "hot-side" surface temperature $\left({ }^{\circ} \mathrm{F}\right)$ for the inner and outer elements at BOC and EOC
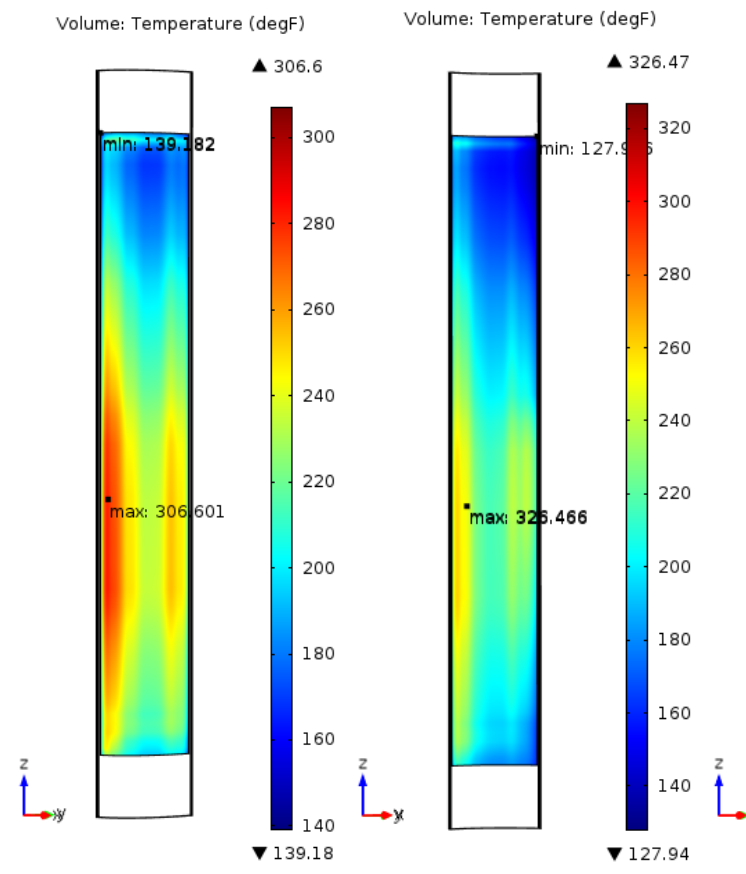

(a) Inner and outer plate at BOC

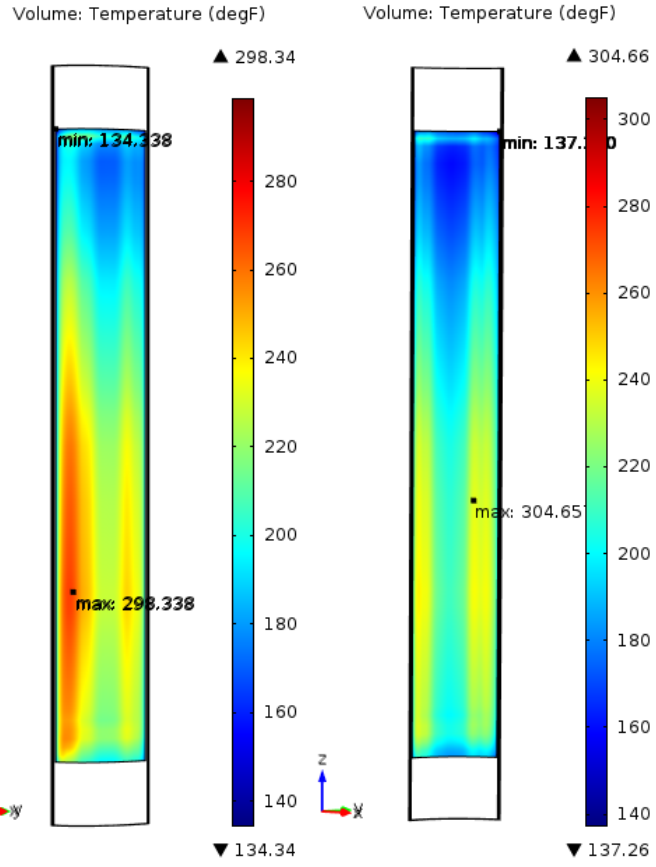

(b) Inner and outer plate at EOC

Fig. 23. COMSOL profiles of fuel meat centerline (peak) temperature $\left({ }^{0} \mathrm{~F}\right)$ for the inner and outer elements at BOC and EOC. 


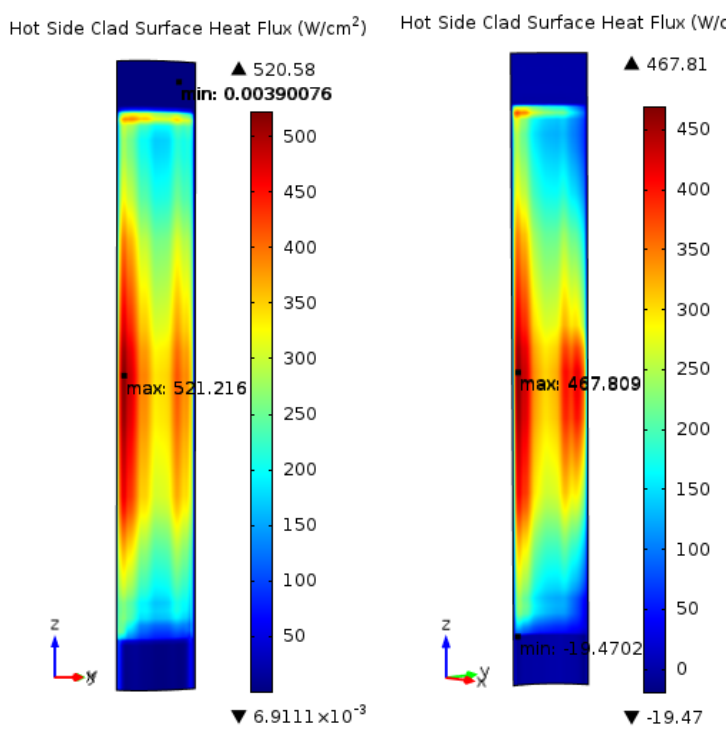

(a) Inner and outer plate at BOC
Hot Side Clad Surface Heat Flux $\left(W / \mathrm{cm}^{2}\right) \quad$ Hot Side Clad Surface Heat Flux $\left(W / \mathrm{cm}^{2}\right)$
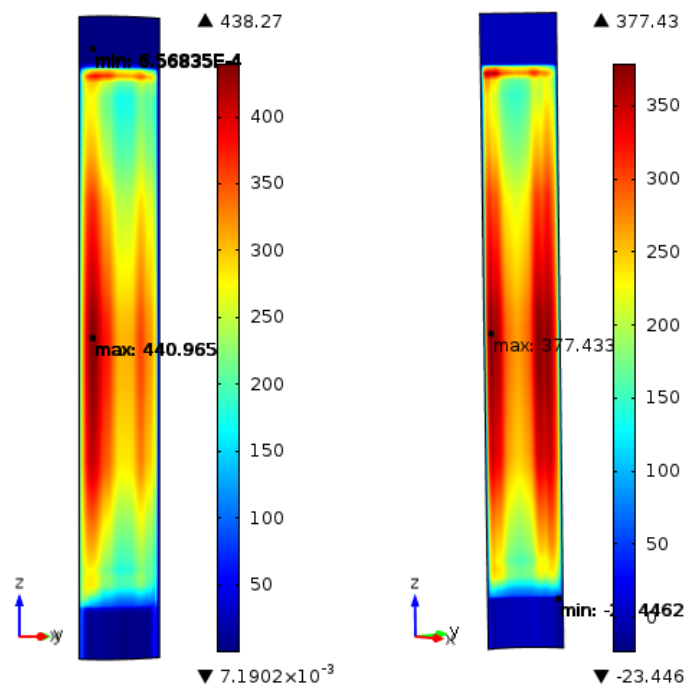

(b) Inner and outer plate at EOC

Fig. 24. COMSOL profiles of plate "hot-side" surface heat flux $\left(W / \mathrm{cm}^{2}\right)$ for the inner and outer elements at BOC and EOC.

Table 10. Peak surface temperatures, heat fluxes, and fuel meat temperatures over the fuel cycle-HSSHTC and COMSOL results

\begin{tabular}{|c|c|c|c|c|c|c|}
\hline $\begin{array}{l}\text { Time in } \\
\text { fuel cycle }\end{array}$ & $\begin{array}{c}\text { HSSHTC } \\
\text { max surface } \\
\text { temperature, } \\
\underset{{ }^{0} F}{ }\end{array}$ & $\begin{array}{c}\text { COMSOL } \\
\text { max surface } \\
\text { temperature, } \\
{ }_{{ }^{0} \mathrm{~F}}\end{array}$ & $\begin{array}{c}\text { HSSHTC } \\
\text { max Heat } \\
\text { Flux, } \\
\text { W/cm² }\end{array}$ & $\begin{array}{l}\text { COMSOL } \\
\text { max Heat } \\
\text { Flux, W/cm² }\end{array}$ & $\begin{array}{c}\text { HSSHTC max } \\
\text { U-Mo meat } \\
\text { temperature, } \\
{ }^{0} \mathbf{F}\end{array}$ & $\begin{array}{c}\text { COMSOL } \\
\text { max U-Mo } \\
\text { meat } \\
\text { temperature, } \\
{ }^{0} \mathrm{~F}\end{array}$ \\
\hline $\begin{array}{l}\text { BOC Inner } \\
\text { Element }\end{array}$ & 261.4 & 263.0 & 530.5 & 521.2 & 282.1 & 306.6 \\
\hline $\begin{array}{l}\text { EOC Inner } \\
\text { Element }\end{array}$ & 252.5 & 250.6 & 467.6 & 441.0 & 290.9 & 298.3 \\
\hline $\begin{array}{c}\text { BOC } \\
\text { Outer } \\
\text { Element }\end{array}$ & 252.0 & 267.5 & 550.8 & 467.8 & 283.9 & 326.5 \\
\hline $\begin{array}{c}\text { EOC } \\
\text { Outer } \\
\text { Element }\end{array}$ & 255.6 & 249.8 & 481.7 & 377.4 & 301.0 & 304.7 \\
\hline
\end{tabular}


Table 11. Determination of peak U-Mo meat temperatures at core axial centerline using HSSHTC results

Inner Element at Inner Edge

\begin{tabular}{c|c|c|c|c|c|c}
\hline $\begin{array}{c}\text { Time in } \\
\text { fuel cycle } \\
\text { BOC-to- } \\
\text { EOC } \\
\text { (26 days) }\end{array}$ & $\begin{array}{c}\text { Inner } \\
\text { element } \\
\text { surface } \\
\text { tempera } \\
\text { ture, }{ }^{\circ} \mathrm{F}\end{array}$ & $\begin{array}{c}\text { Inner } \\
\text { Element } \\
\text { Heat } \\
\text { Flux, } \\
\mathrm{W} / \mathrm{cm}^{2}\end{array}$ & $\begin{array}{c}\text { Local } \\
\text { power } \\
\text { density, } \\
\mathrm{W} / \mathrm{cm}^{3}\end{array}$ & $\begin{array}{c}\text { Oxide } \\
\text { thickness, } \\
\text { mils }\end{array}$ & $\begin{array}{c}\text { Local } \\
\text { meat } \\
\text { average } \\
\text { thickness, } \\
\mathrm{cm}\end{array}$ & $\begin{array}{c}\text { Peak meat } \\
\text { temperature, } \\
{ }^{\circ} \mathrm{F}\end{array}$ \\
\hline BOC & 254.3 & 530.5 & 72249 & 0.0 & .00973 & 282.1 \\
\hline $\begin{array}{c}\text { Peak } \\
\text { xenon } \\
\text { (Day 1) }\end{array}$ & 247.4 & 498.9 & 68500 & 0.03 & .00973 & 276.9 \\
\hline $\begin{array}{c}\text { EOC } \\
\text { (day 26) }\end{array}$ & 242.1 & 467.6 & 45297 & 0.33 & .00973 & 290.9 \\
\hline
\end{tabular}

Outer Element at Outer Edge

\begin{tabular}{c|c|c|c|c|c|c}
\hline $\begin{array}{c}\text { Time in } \\
\text { fuel cycle } \\
\text { BOC-to- } \\
\text { EOC } \\
\text { (26 days) }\end{array}$ & $\begin{array}{c}\text { Outer } \\
\text { element } \\
\text { surface } \\
\text { tempera } \\
\text { ture, }{ }^{\circ} \mathrm{F}\end{array}$ & $\begin{array}{c}\text { Outer } \\
\text { Element } \\
\text { Heat } \\
\text { Flux, } \\
\mathrm{W} / \mathrm{cm}^{2}\end{array}$ & $\begin{array}{c}\text { Local } \\
\text { power } \\
\text { density, } \\
\mathrm{W} / \mathrm{cm}^{3}\end{array}$ & $\begin{array}{c}\text { Oxide } \\
\text { thickness, } \\
\text { mils }\end{array}$ & $\begin{array}{c}\text { Local } \\
\text { meat } \\
\text { average } \\
\text { thickness, } \\
\mathrm{cm}\end{array}$ & $\begin{array}{c}\text { Peak meat } \\
\text { temperature, } \\
{ }^{\circ} \mathrm{F}\end{array}$ \\
\hline BOC & 250.1 & 550.8 & 43684 & 0.0 & .0160 & 283.9 \\
\hline $\begin{array}{c}\text { Peak } \\
\text { cenon } \\
\text { (Day 1) }\end{array}$ & 261.5 & 590.17 & 47200 & 0.03 & .0160 & 301.8 \\
\hline $\begin{array}{c}\text { EOC } \\
\text { (day 26) }\end{array}$ & 241.8 & 468.4 & 35866 & 0.33 & .0160 & 301.0 \\
\hline
\end{tabular}

\subsection{THERMAL CONDITIONS AT LOCATIONS OF PEAK FISSION RATE AND ACCUMULATED FISSION DENSITY}

Peak surface temperatures, heat fluxes, and fuel meat temperatures for various times in the cycle are shown in Table 12 for the inner element and in Table 13 for the outer element. For the inner element, the maximum surface temperature of $261.4^{\circ} \mathrm{F}$ occurs at the BOC, near the inner edge at $\mathrm{r}=8.5 \mathrm{~cm}$ from the core radial centerline, and at an axial location slightly below the core centerline, at $33.8 \mathrm{~cm}$ from TOAF. The peak heat flux of $530.5 \mathrm{~W} / \mathrm{cm}^{2}$ for the inner element also occurs at the BOC, at the same radial location as the peak temperature, but at the core centerline, which is $25.4 \mathrm{~cm}$ from TOAF.

For the outer element, the peak surface temperature of $265.7^{\circ} \mathrm{F}$ occurs at day 1 of the cycle, near the outer edge at $\mathrm{r}=21.0 \mathrm{~cm}$ from the core radial centerline, and at an axial location slightly below the core centerline, at $33.8 \mathrm{~cm}$ from TOAF. The peak heat flux of $590.2 \mathrm{~W} / \mathrm{cm}^{2}$ for the outer element also occurs at day 1 , at the same radial location as the peak surface temperature, but at the core centerline, which is $25.4 \mathrm{~cm}$ from TOAF. 
The center, inside edge of the inner element was chosen as a fixed reference point to characterize the evolution of the inner element peak fuel meat temperature during a cycle. Table 12 shows the peak temperatures of the meat versus time in the cycle for this location, based on the HSSHTC results for hot side surface temperature, hot side heat flux, and calculated oxide thickness together with information from the MCNP model for the nodal power density and average fuel meat thickness. A one-dimensional conduction model of the fuel with heat generation in the fuel meat region and asymmetric aluminum cladding thicknesses was used to determine the peak meat temperature, which was located slightly offcenter in the meat toward the thick cladding side.

Table 13 provides the peak fuel meat temperature for the outer element similar to Table 12 for the inner element. The reference location for the outer element is the outside edge at $\mathrm{r}=21.0 \mathrm{~cm}$ from the radial core centerline.

Based on the results in Table 12 for the inner element, we recommend irradiation sample surface temperature, heat flux, and fuel meat temperature minimum conditions for nominal operation to be 260 ${ }^{\circ} \mathrm{F}, 530 \mathrm{~W} / \mathrm{cm}^{2}$, and $300{ }^{\circ} \mathrm{F}$, respectively.

Based on the results in Table 13 for the outer element, we recommend irradiation sample surface temperature, heat flux, and fuel meat temperature minimum conditions for nominal operation to be 260 ${ }^{\circ} \mathrm{F}, 590 \mathrm{~W} / \mathrm{cm}^{2}$, and $300{ }^{\circ} \mathrm{F}$, respectively. 
Table 12. Peak surface temperatures, heat fluxes, and fuel meat temperatures for the inner element over the fuel cycle

\begin{tabular}{|c|c|c|c|c|c|}
\hline $\begin{array}{c}\text { Time in } \\
\text { fuel } \\
\text { cycle } \\
\begin{array}{c}\text { BOC-to- } \\
\text { EOC (26 } \\
\text { days) }\end{array}\end{array}$ & $\begin{array}{c}\text { Inner } \\
\text { element } \\
\text { max } \\
\text { surface } \\
\text { Temp, } \\
{ }^{\circ} \mathrm{F}\end{array}$ & $\begin{array}{c}\text { Inner } \\
\text { element } \\
\text { max } \\
\text { Heat } \\
\text { Flux, } \\
\mathrm{W} / \mathrm{cm}^{2}\end{array}$ & $\begin{array}{c}\text { Inner } \\
\text { element } \\
\text { core axial } \\
\text { centerline } \\
\text { surface } \\
\text { Temp, }{ }^{\circ} \mathrm{F}\end{array}$ & $\begin{array}{c}\text { Inner } \\
\text { element } \\
\text { core axial } \\
\text { centerline } \\
\text { Heat } \\
\text { Flux, } \\
\mathrm{W} / \mathrm{cm}^{2}\end{array}$ & $\begin{array}{c}\text { Inner } \\
\text { element } \\
\text { core axial } \\
\text { centerline } \\
\text { peak U- } \\
\text { Mo meat } \\
\text { Temp., }{ }^{\circ} \mathrm{F}\end{array}$ \\
\hline BOC & 261.4 & 530.5 & 254.3 & 530.5 & 282.1 \\
\hline $\begin{array}{c}\text { Peak } \\
\text { xenon } \\
\text { (day 1) }\end{array}$ & 255.0 & 498.9 & 247.4 & 498.9 & 276.9 \\
\hline EOC & 252.5 & 467.6 & 242.1 & 467.6 & 290.9 \\
\hline
\end{tabular}

Table 13. Peak surface temperatures, heat fluxes, and fuel meat temperatures for the outer element over the fuel cycle

\begin{tabular}{|c|c|c|c|c|c|}
\hline $\begin{array}{c}\text { Time in } \\
\text { fuel } \\
\text { cycle } \\
\begin{array}{c}\text { BOC-to- } \\
\text { EOC (26 } \\
\text { days) }\end{array}\end{array}$ & $\begin{array}{c}\text { Outer } \\
\text { element } \\
\text { max } \\
\text { surface } \\
\text { Temp, } \\
{ }^{\circ} \mathrm{F}\end{array}$ & $\begin{array}{c}\text { Outer } \\
\text { element } \\
\text { max Heat } \\
\text { Flux, } \\
\mathrm{W} / \mathrm{cm}^{2}\end{array}$ & $\begin{array}{c}\text { Outer } \\
\text { element } \\
\text { core axial } \\
\text { centerline } \\
\text { surface } \\
\text { Temp, }{ }^{\circ} \mathrm{F}\end{array}$ & $\begin{array}{c}\text { Outer } \\
\text { element } \\
\text { core axial } \\
\text { centerline } \\
\text { Heat } \\
\text { Flux, } \\
\mathrm{W} / \mathrm{cm}^{2}\end{array}$ & $\begin{array}{c}\text { Outer } \\
\text { element } \\
\text { core axial } \\
\text { centerline } \\
\text { peak U-Mo } \\
\text { meat } \\
\text { Temp., }{ }^{\circ} \mathrm{F}\end{array}$ \\
\hline $\begin{array}{c}\text { BOC } \\
\text { Peak } \\
\text { (day 1) }\end{array}$ & 252.0 & 550.8 & 250.1 & 550.8 & 283.9 \\
\hline EOC & 255.6 & 481.7 & 241.8 & 468.4 & 301.8 \\
\hline
\end{tabular}





\section{CONCLUSIONS}

Based on MCNP calculations of the HFIR fission rate density, it is recommended that a minimum irradiation sample fission rate density of $1.3 \times 10^{15}$ fissions $/ \mathrm{cm}^{3} \mathrm{UMo}$-s be used to represent the inner element and a minimum of $1.0 \times 10^{15}$ fissions $/ \mathrm{cm}^{3} \mathrm{UMo}$-s be used to represent the outer element. Based on MCNP calculations of the HFIR accumulated fission density, it is recommended that a minimum irradiation sample accumulated fission density of $3.25 \times 10^{21}$ fissions $/ \mathrm{cm}^{3} \mathrm{UMo}$ be used for the inner element and $2.25 \times 10^{21}$ fissions $/ \mathrm{cm}^{3} \mathrm{UMo}$ be used for the outer element.

Based on HSSHTC core cycle calculations, which were independently compared against a nominal COMSOL single plate/single channel model, we recommend irradiation sample surface temperature, heat flux, and fuel meat temperature minimum conditions to be $260{ }^{\circ} \mathrm{F}, 530 \mathrm{~W} / \mathrm{cm}^{2}$, and $300{ }^{\circ} \mathrm{F}$ for the inner element and $260{ }^{\circ} \mathrm{F}, 590 \mathrm{~W} / \mathrm{cm}^{2}$, and $300^{\circ} \mathrm{F}$ for the outer element. Based on the COMSOL comparisons, it is recognized that the peak U-Mo meat temperatures obtained with the HSSHTC may be slightly under-predicted. Before a final experimental testing specification is complete, confirmatory calculations of the nominal conditions should be issued including a more complete comparison between COMSOL and HSSHTC results. 



\section{REFERENCES}

1. G. Ilas and R. T. Primm III, Low Enriched Uranium Fuel Design with Two-Dimensional Grading for the High Flux Isotope Reactor, ORNL/TM-2010/318, Oak Ridge National Laboratory (2011).

2. X-5 Monte Carlo Team, MCNP-A General Monte Carlo N-Particle Transport Code, Version 5, LA-CP-03-0245, Los Alamos National Laboratory (2003).

3. W. Haeck, VESTA User's Manual-Version 2.0.0, IRSN Report DSU/SEC/T/2008-331 Indice A, France (2009).

4. SCALE: A Modular Code System for Performing Standardized Computer Analyses for Licensing Evaluation, ORNL/TM-2005/39, Version 6, Vols. I-III, January 2009. (Available from Radiation Safety Information Computational Center at Oak Ridge National Laboratory as CCC-750).

5. N. Xoubi and R. T. Primm III, Modelling of the High Flux Isotope Reactor Cycle 400, ORNL/TM2004-251 (2005).

6. Howard A. McLain: HFIR Fuel Element Steady State Heat Transfer Analysis, Revised Version. ORNL-TM-1904, (1967).

7. T. E. Cole, L. F. Parsly, \& W. E. Thomas: "Revisions to HFIR Fuel Element Steady State Heat Transfer Analysis Code”, ORNL/CF-85/68, (April 7, 1986).

8. J.D. Freels and P.K. Jain, Multiphysics Simulations of the Complex 3D Geometry of the High Flux Isotope Reactor Fuel Elements Using COMSOL, COMSOL Conference, Boston, October 2011.

9. COMSOL Multiphysics Version 4.3 User Guide, www.comsol.com. 